\title{
Necrópolis Ibérica de «El Cigarrale- jo». Estudio osteológico (comparado con los ajuares)
}

\author{
M. SANTONJA ALONSO *
}

\section{INTRODUCCIÓN}

La Necrópolis Ibérica de «El Cigarralejo» está situada en el término municipal de Mula (Murcia) a unos $3 \mathrm{~km}$ de su núcleo urbano.

El estudio de esta necrópolis es un ejemplo a seguir, que rompe el panorama de los muchos yacimientos ibéricos similares, insuficientemente estudiados y publicados, así como el de la acumulación de materiales, que permanecen inéditos en los museos, y también la carencia de estudios osteológicos de los restos óseos, cuestiones que se han visto resueltas: con la publicación de su conocida Monografía ${ }^{1}$, con el presente trabajo y con la visita al Museo de El Cigarralejo, en la ciudad de Mula, modélico en todo y digno colofón del estudio de esta necrópolis, lugar de destino de todo aquel que quiera conocer o profundizar en el pasado mundo ibérico.

En nuestro país se ha prestado poca atención a los estudios osteológicos en las necrópolis ibéricas, debido al desinterés de los arqueólogos hacia esos estudios y, en gran parte, por la dificultad de encontrar especialistas en la materia y que muestren inclinación a participar en las duras tareas de una excavación.

Últimamente, se asiste a un cambio de actitud por parte de todos y se van abriendo nuevos cauces en estas investigaciones, tanto de tipo interdisciplinar como de laboratorio, que permitirán responder mejor a las

* Asociación Española de Amigos de la Arqueología.

Monografía La Necrópolis Ibérica de El Cigarralejo (Mula, Murcia), E. Cuadrado, Biblioteca Praehistorica Hispana, XXIII. Madrid 1987. 
interrogantes planteadas sobre edad, sexo, paleopatología y otras, siendo deseable, en esta coyuntura, llegar a unificar terminologías y métodos y, también, conseguir una mejor difusión bibliográfica de estos trabajos, a los que se debe despojar de toda carga de subjetividad que en nada los favorece.

Por todo ello, parecia inconcebible disponer del espléndido material de El Cigarralejo sin darlo a conocer, dada la general desinformación que han venido dando, por sus circunstancias, las excavaciones anteriores, situación que ha quedado resuelta.

La cronología de la necrópolis abarca desde finales del siglo $v$ a.C. al siglo । d.C., fundamentalmente del año 465 a.C al 50 d.C, siendo su apogeo en el siglo IV y su ritural funerario la cremación.

El número de tumbas excavadas por D. Emeterio Cuadrado, durante los más de 40 años en los que se desarrollaron los trabajos, asciende a 548. De ellas están publicadas en la Monografía 382 y de su total se han estudiado osteológicamente 187 , un 34,12 por 100 , que se exponen a continuación de esta introducción.

Esta «muestra» es el resultado de la investigación desde el punto de vista de la anatomía, en su rama de osteología y la métrica, con las observaciones de índole patológica, sobre los restos óseos cremados de cada una de las tumbas, muy variables de unas a otras. En los Boletines de la Asociación Española de Amigos de la Arqueología, n. ${ }^{\circ} 21$, págs. 4657,$1985 ;$ n. ${ }^{\circ} 22$, págs. $28-36,1986$; n. ${ }^{\circ} 27$, págs. $56-60,1989$, y n. ${ }^{\circ} 32$ donde se exponen extensamente métodos de trabajo, razonamientos, dudas y conclusiones.

Si los datos obtenidos en antropología física, trabajando sobre esqueletos, más o menos completos, están sujetos a errores, podemos comprender cómo serán éstos al disponer solamente de fragmentos óseos y eso en el mejor de los casos. De aquí que las conclusiones sobre Paleodemografía resulten tan frágiles y discutibles, por lo que no se deben manipular, haciéndoles «decir» lo que no dicen, para su tratamiento informático y estadístico.

En las necrópolis ibéricas, estudiadas hasta ahora, se va confirmando el hecho de "no reflejar todas las muertes del poblado», "que sólo están enterradas las "élites" y sus deudos" y que con el resto de la población se siguió un rito más simple o están en otro lugar.

\section{TÉCNICAS DE INVESTIGACIÓN}

El incesante avance en bioquímica ha propiciado nuevos caminos en osteología pero, en nuestro caso particular, con la cremación, los huesos 
han debido sufrir profundos cambios pendientes de investigar o aparecer en nuestra bibliografía.

En Cigarralejo hemos seguido las normas clásicas de la Anatomía descriptiva, morfológica y métrica, en lo que ha sido posible, para determinar edad y sexo. Es indudable que la osteología ha rendido al máximo en estos casos y no se le puede pedir más y aquí está el peligro de las opiniones subjetivas. Las medidas obtenidas habrá que someterlas a controversia dadas las alteraciones que sufren los huesos en la cremación y, por ello, la necesidad de ir a la confección de un "banco de datos" que nos facilite una base en el futuro, dada la iniciación de estos estudios entre nosotros.

Estimo que para datar la edad, el camino más efectivo es hacer tres o cuatro grupos:

Infantiles: de 0 a 7 años (inicio de dentición permanente).

Púberes: de 7 a 14 años (dentición permanente, sin M3 y epífisis sin soldar).

Juveniles: de 14 a 25 años (soldadura de epífisis, M3).

Adultos: + 25 años... [término del crecimiento. Cierre de suturas craneales ( $i ?)]$.

En el capítulo de la datación del sexo de los cremados, ésta resulta muy a menudo imposible, especialmente en las primeras edades, de aquí la necesidad de establecer el grupo de los alofixos o indeterminados. Por todo ello, al menos en Cigarralejo, fue de considerable ayuda disponer del contenido del ajuar para de modo secundario, es decir, una vez terminada la diagnosis osteológica, contrastar uno con otro, especialmente en los alofixos y en los casos de varones gráciles o de hembras fornidas.

En un trabajo de E. Kunter sobre los restos esqueléticos de El Argar y El Oficio, correspondientes a la edad del Bronce, destaca expresamente que "la determinación del sexo se hizo independientemente de los ajuares", dado que en otros trabajos los ajuares han tenido "el peso de un determinante biológico", criterio que puede ser mantenido en nuestros casos al ser el material óseo totalmente diferente, pero insisto en que, para nosotros, contrastar análisis osteológico con ajuar ha sido de gran ayuda para la determinación del sexo del sujeto cremado. Otro hecho importante a destacar es la escasa presencia de piezas dentarias, a pesar de que se practicó el doble cribado de tierras y cenizas.

\section{TUMBAS DOBLES}

Al igual que en otras necrópolis, se planteó en ésta el problema de las tumbas "dobles", a veces de difícil solución por la posible "mezcla» 


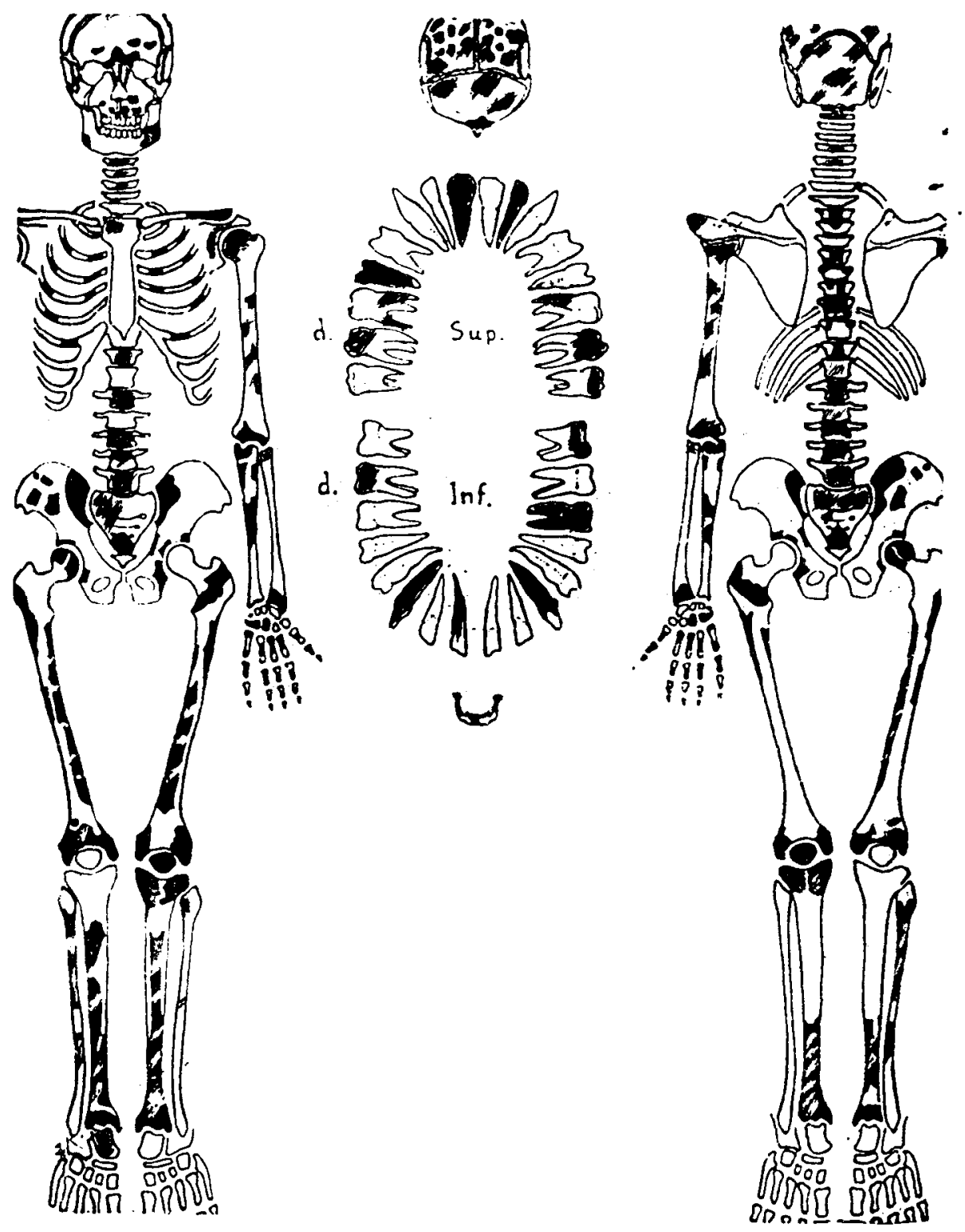

Fig. 1. En sombreado fragmentos recogidos con mayor frecuencia. 
al recoger los restos cremados, pero en parte de los casos por la presencia de dos "enterramientos", individualizados, en una sola tumbra y en otros por identificarse los restos de dos individuos en un solo "paquete", en un solo contenido, con un solo tipo de ajuar, casos en los que propiamente sería una tumba doble, producto de una sola cremación o simultánea. Para mayor información consultar las tumbas siguientes:

T: 118, 125, 140, 204, 209, 223, 247, 261, 293, 298 (?), 333, 382, 390, $399, \mathrm{~s} / \mathrm{n} .^{\circ} 1, \mathrm{~s} / \mathrm{n} .^{\circ} 2, \mathrm{~s} / \mathrm{n} .^{\circ} 3,504,518,528,534,541$ y 545.

En su mayoría están entremezclados restos de niño menor de un año y hembra, siendo muy escasos, y en general craneales, los fragmentos infantiles, que se identifican bien por no estar cremados. Las tumbras infantiles estudiadas son las números:

De 0 a 12 meses: 118, 140, 162, 201, 261, 247, 317, 371, 406, $\mathrm{s} / \mathrm{n} .^{\circ} 10$.

De 12 meses a 7 años: $214,292,299,399, s / n .^{\circ} 1, s / n .^{\circ} 2, s / n .^{\circ} 11$, $498,500,504,518,528,534$ y 541 .

La paleopatología está documentada con la presencia de lesiones de artritis y artrosis vertebrales, descritas en las tumbas:

$22,92,118,125, \mathrm{~A} / \mathrm{B}, 128,158,196,236,298,308,333,382,390$, $399,400,411,413,534$ y 545 .

Como ejemplo de lo complejo que resulta, a veces, el análisis osteológico consultar la tumba 534.

En los anteriormente referidos Boletines se publican: en el $n .^{\circ} 21$ abundante iconografía sobre restos óseos cremados y de las alteraciones patológicas; en el $n .^{\circ} 22$ las razones para establecer el grupo de los alofixos o de sexo indeterminado anatómicamente y en el n. ${ }^{\circ} 27$, págs. 56 y ss., tablas de valores y porcentajes de los 164 estudiados hasta aquellas fechas (cuyos cuadros se reproducen), que sufren poca variación al agregar los 27 casos últimamente examinados, según se puede apreciar en los valores siguientes:

Número de cremados

Varones

$68(36,36 \%)$

Hembras

$80 \quad(42,78 \%)$

Alofixos

$15 \quad(8,02 \%)$

Infantiles

$24(12,83 \%)$ 


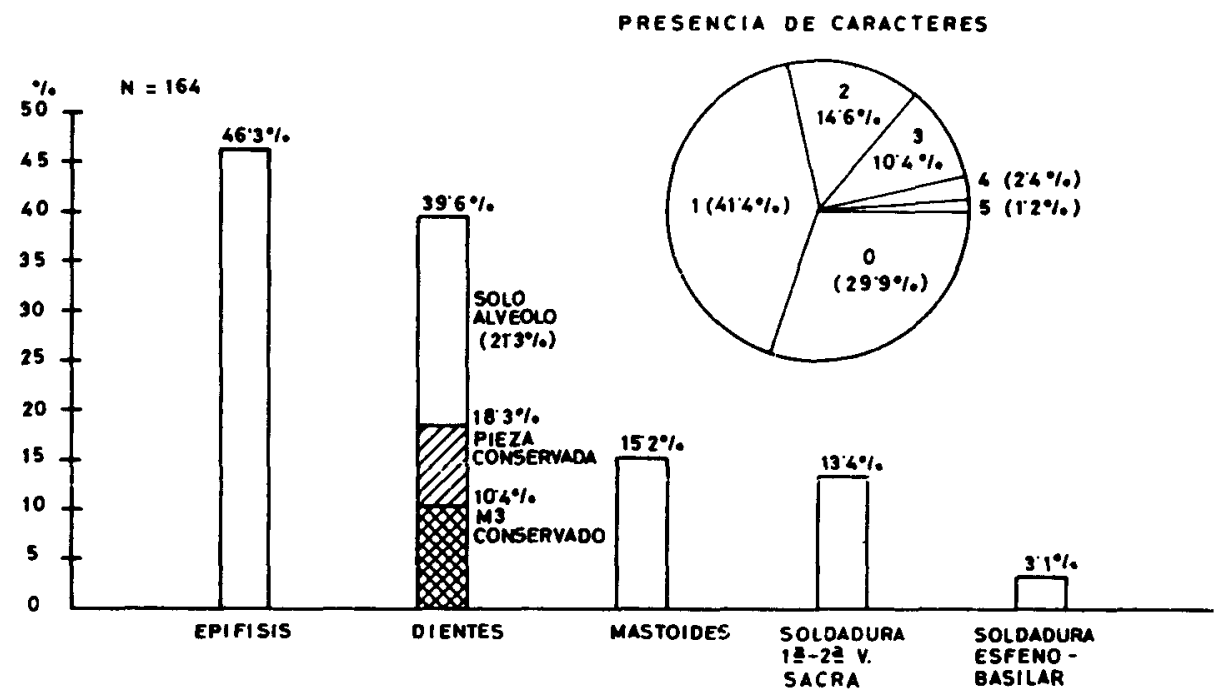

Fig. 2. Porcentajes óseos específicos y $n .^{\circ}$ de casos sobre 164: Epífisis, 76 Dientes, 65 (alvéolos, 35. M3, 17). Mastoides, 25. Soldadura $1 .^{a}$ a $2 .^{a}$ vértebra del Sacro, 22. Soldadura esfeno-basilar, 5 .

\section{TUMBAS}

T. 22. (Existe otra signatura de T: 197/A ?). Contenido óseo: 31, entre fragmentos y esquirlas. CRÁNEO: láminas sin soldar. Grosores de $6 \mathrm{~mm}$. Maxilares con bordes alveolares y paladar. El derecho un $1^{2}-M^{1}$ y $M^{2}$ con usura de $4 .^{\circ}$ grado. M1 y $\mathrm{M} 2$ emergiendo. Velo de paladar: ancho (nivel de M1) 30-32 mm ?. Largo, $36 \mathrm{~mm}$. Índice, 83-88?. Abertura nasal en naipe francés y sus medidas ??: ancho $18 \mathrm{~mm} x$ alto $17 \mathrm{~mm}$ ?. Índice, 94,44 (?). VÉRTEBRAS: lumbares, parte de tres cuerpos. Bordes con «sindesmofitos" y carillas soldadura inicial. Medidas: diámetros, $28 \mathrm{~mm}$ ? x $41 \mathrm{~mm}$ ?. Alturas de 21 a $23 \mathrm{~mm}$. EXTREMIDADES: húmero, cabeza incompleta, soldadura a término. Fragmento de diáfisis, diámetro $14 \times$ $18 \mathrm{~mm}$ a nivel (?).

Resumen: individuo joven, 16 años (?)-18 años ?. Alofixo. Ajuar ambiguo.

T. 37 y 38. Examinados los restos óseos: 33 fragmentos y esquirlas. CRÁNEO: fragmento de protuberancia occipital interna de poco volumen. Maxilar superior con parte de borde alveolar y paladar. $\mathrm{M}^{1}$ derecho alvéolo y los demás morales sin emerger. Velo paladar: $32 \times 33 \mathrm{~mm}$. Índice, 96,96. Indice de la arcada dentaria, 123 -restos estallados de $\mathrm{I}^{2}$ y $\mathrm{P}^{2}$. VÉRTE- 


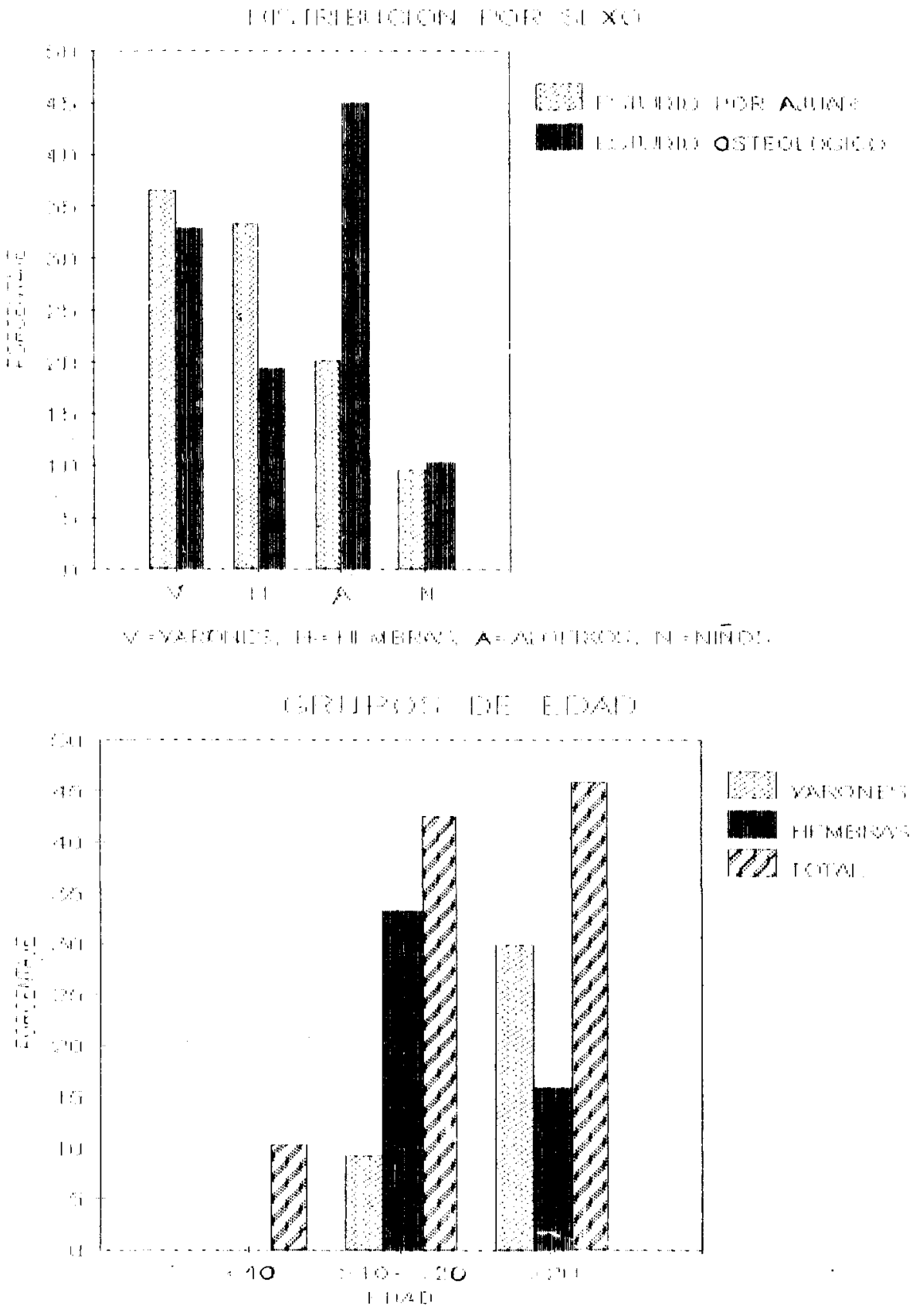

Fig. 3. 


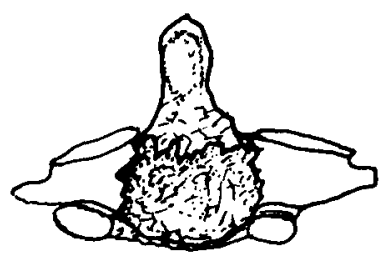

$2^{2}$ V. Cervical

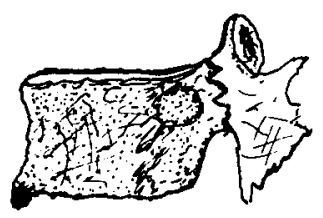

v. Dorsal
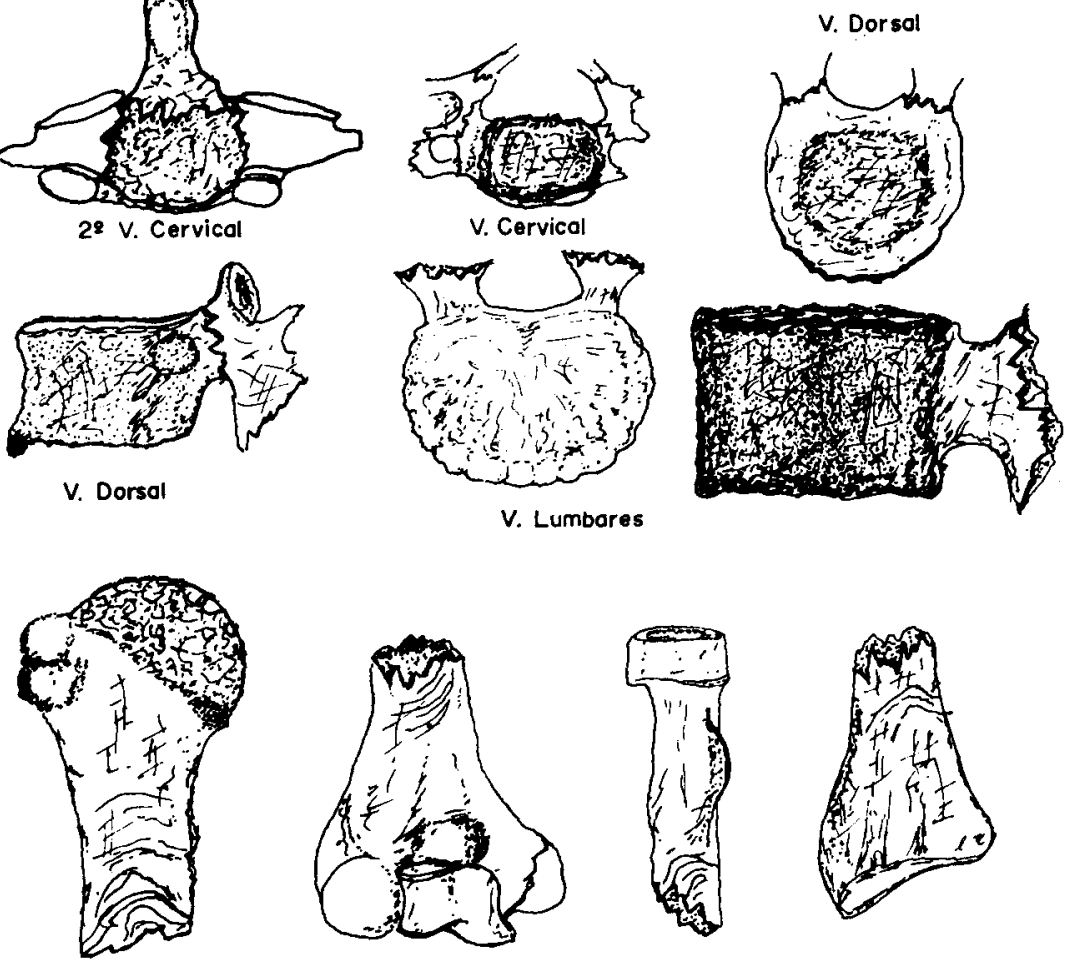

Epifisis Humero

(Cobeza)
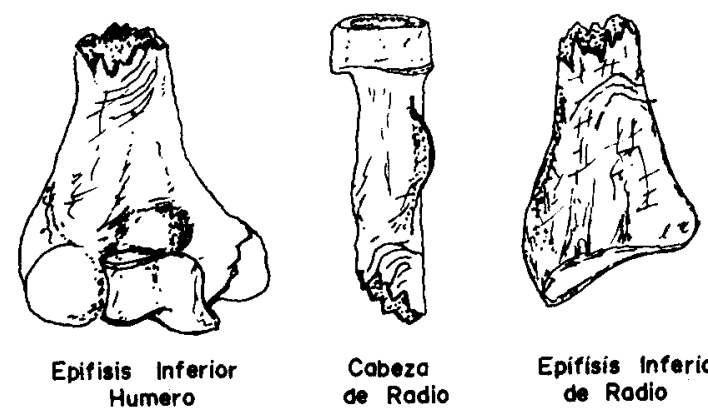
Epitisis Interior de Rodio
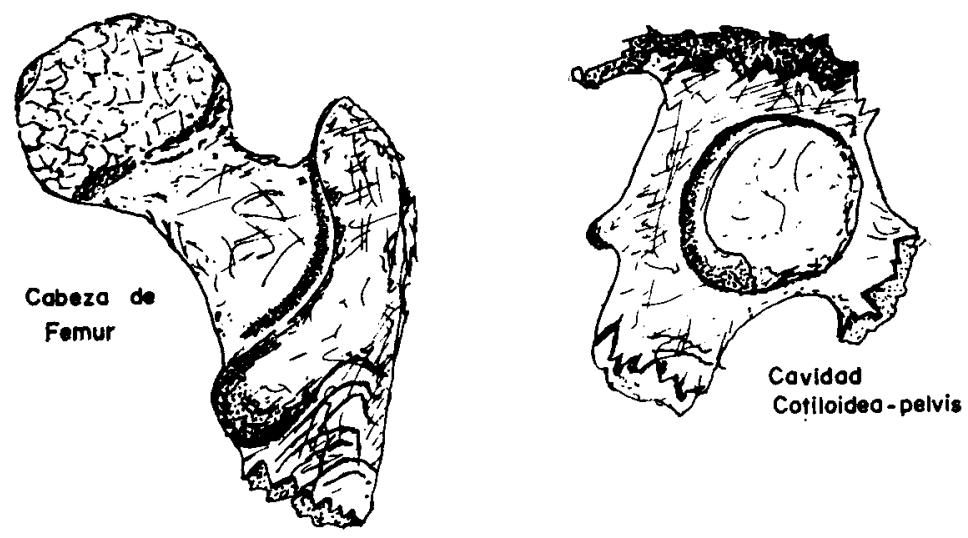

Fig. 4. Fragmentos más frecuentes. 
BRAS: $2 .^{a}$ vértebra cervical o axis, retraída, deforme; su altura total, $26 \mathrm{~mm}$; de la odontoides, $12 \mathrm{~mm}$. Diámetros, $10 \times 18 \mathrm{~mm}$. Índice, 57,14. Diámetro transverso total, $40 \mathrm{~mm}$. ¿Canal raquídeo, $12 \times 21 \mathrm{~mm}$ Índice, 57,14 . EXTREMIDADES: fragmento de coxal. Diámetro cavidad cotiloidea, $32 \mathrm{~mm}$ ? Fragmento cabeza de fémur, terminando soldadura y concuerda con cotilo.

Resumen: individuo juvenil (pubertad) entre 8-10 años. Alofixo. El ajuar con cerámicas y fusayola.

T. 81. Sin ajuar. Restos óseos: DIENTES: fragmento de corona de M1 - con usura de $1 .^{\circ}$ y corona de $\mathrm{M} 2$ - sin usura, por lo que la edad del individuo estaría cercana a la erupción.

Resumen: niño-a entre 12-14 años.

T. 92. Examinados los restos óseos: 42 fragmentos y esquirlas. CRÁNEO: frontal, iniciada soldaduras en cara interna. Grosor, 6-8 mm. Parietal, sinóstosis interna, iniciada externa. Grosor, $8 \mathrm{~mm}$. Occipital, parte de agujero de diámetro pequeño. Mandíbula sólo cóndilo izquierdo de $7 \times$ $19 \mathrm{~mm}$. Índice, 36,84 . VÉRTEBRAS: partes de cuerpos vértebras dorsales, retraídos y deformes. «Sindesmofitos". Diámetros, $29 \times 42 \mathrm{~mm}$. Índice, 69. Alturas sobre $26 \mathrm{~mm}$ ?? Apófisis deformes y estalladas. Vértebras lumbares, partes de cuerpos, retraídos y deformados con "sindesmofitos" $y$ "Osteofitos", formando excrescencias coincidentes. Diámetros, 33 × $48 \mathrm{~mm}$ ?? Índice, 68,77 ?? Alturas sobre $26 \mathrm{~mm}$. EXTREMIDADES: omóplato, sólo cavidad glenoidea incompleta. Altura del cuello $27 \mathrm{~mm}$. Húmero, espesor de lámina 4-6 mm. Fémur, fragmento cabeza o bola articular derecha (1). Diámetro, $46 \times 42 \mathrm{~mm}$ ?? Cuello, $34 \mathrm{~mm}$ ?? Líneas de fractura y semilunas, «eburneación» intensa. Espesor de láminas, $6 \mathrm{~mm}$. Diámetro a $\mathrm{n}$ / 1: áspera entre 22-26 mm (ver dibujo en págs. 18-19).

Resumen: individuo varón, mayor de 20 años. Existen en el ajuar manillas de escudo, pasador sujeción falcata, cerámica ática.

T. 107. Examen anatómico de los restos óseos: 152 fragmentos y esquirlas. CRÁNEO: láminas soldadas. Suturas de pequeños dentellones, sin soldar. Grosores de 5 a $9 \mathrm{~mm}$. Reborde orbital redondeado, fuerte. Peñascos derecho-izquierdo de buen tamaño, soldado. Orificio auditivo interno de $14 \mathrm{~mm}$. Molares derecho-izquierdo. Mandíbula, fragmento de apósifis coronoides izquierda de tamaño medio y otro fragmento de rama con M3 y usura de $4 .^{\circ}$ VÉRTEBRAS: $2 .^{\text {a }}$ vértebra cervical o axis incompleta. Altura total, $29 \mathrm{~mm}$. Ídem de la odontoides, $13 \mathrm{~mm}$. Diámetros: anteroposterior máximo, $43 \mathrm{~mm}$; del cuerpo, $14 \times 18 \mathrm{~mm}$. Índice, 77,7; del canal raquídeo, $16 \times 17 \mathrm{~mm}$. Índice, 94,1 . Apófisis espinosa de la $77^{\circ}$, de $29 \mathrm{~mm}$. Fragmento de cuerpo de vértebra lumbar, carillas soldadas. Altura de 
$23 \mathrm{~mm}$. EXTREMIDADES: cabeza de húmero izquierdo. Diámetro, $39 \mathrm{~mm}$. Altura, $31 \mathrm{~mm}$. Soldadura a término. Diámetros en diáfisis sobre $18 \mathrm{~mm}$. Metacarpianos, soldaduras a término. Fragmento de pelvis con cavidad cotiloidea. Diámetros, ? $42 \mathrm{~mm}$. Cabeza de fémur, diametros sobre $40 \mathrm{~mm}$, soldadura a término. Tibia epífisis inf. garganta pie superficie articular $29 \times 40 \mathrm{~mm}$. Parte de astrágalo, que concuerda, y fragmento de metatarsianos, soldados a término.

Resumen: individuo varón, mayor de 25 años. Ajuar: falcata, lanza, fíbulas y restos escultóricos.

T. 108. Examen anatómico de los restos óseos: seis fragmentos. CRÁNEO: solamente existen de los parietales derechos-izquierdos, que permiten calcular el perfil de la curvatura craneal a este nivel. Huellas profundas de la articulación meníngea media. Sutura sagital de grandes dentellones, sin soldar. Grosores de 8 y $9 \mathrm{~mm}$.

EXTREMIDADES: estrías y semilunas de fractura intensa. Eburneación. Grosor de paredes en diáfisis, 2 a $4 \mathrm{~mm}$. Epífisis aplastadas y desprendidas, sin soldar. Cabeza de húmero (2), sus diámetros $35 \times 37 \mathrm{~mm}$. Diámetro en diáfisis, $33 \mathrm{~mm}$. Fragmento del ilíaco, escotadura abierta, redondeada (3) y en otro cavidad cotiloidea que concuerda con cabeza femoral. Porción de cabeza articular femoral derecha muy deforme por la acción del calor, el cuello se ha modificado, quedando casi vertical (4). Soldadura a término. Diámetros en cuello, $17 \times 18 \mathrm{~mm}$. Bola articular, 31 x $36 \mathrm{~mm}$. Alto, $26 \mathrm{~mm}$, medidas para los dos lados. Fragmento de la mesea tibial, impresión de tamaño medio. Otros fragmentos de ROA.

Resumen: individuo joven entre 17-19 años. Alofixo (hembra). Ajuar revuelto.

T. 110. Examen anatómico: 47 fragmentos y esquirlas. CRÁNEO: grosor 5-6 $\mathrm{mm}$ y $14 \mathrm{~mm}$ en protuberancia occipital. VÉRTEBRAS: fragmentos de cuerpos, vértebras cervicales, alturas $11 \mathrm{~mm} \&$ EXTREMIDADES: intensa fracturación, poco grosor de paredes.

Resumen: sexo Alofixo, edad juvenil. Por el ajuar hembra (fusayolas, caracol, tijeras, fíbula, cadena).

T. 112. Examen anatómico: 105 fragmentos y esquirlas. CRÁNEO: láminas saltadas. Suturas de pequeños dentellones, sin soldar. Grosor, 4$6 \mathrm{~mm}$. Órbita pequeña, reborde fino. Peñasco izquierdo sin soldar de 32 x $12 \mathrm{~mm}$. Fragmento de esfenoides. Maxilar, alvéolos de P-P-M1, dientes permanentes. VÉRTEBRAS: cuerpos vértebras dorsales. Diámetros, $23 \times$ $21 \mathrm{~mm}$. Alturas de 16 a $22 \mathrm{~mm}$. En vértebras lumbares, $27 \times 34 \mathrm{~mm}$ y alto sobre $23 \mathrm{~mm}$. Sacro, vértebra primera sin soldar a segunda. Diámetro, $19 \times 24 \mathrm{~mm}$. Alto, $22 \mathrm{~mm}$. 

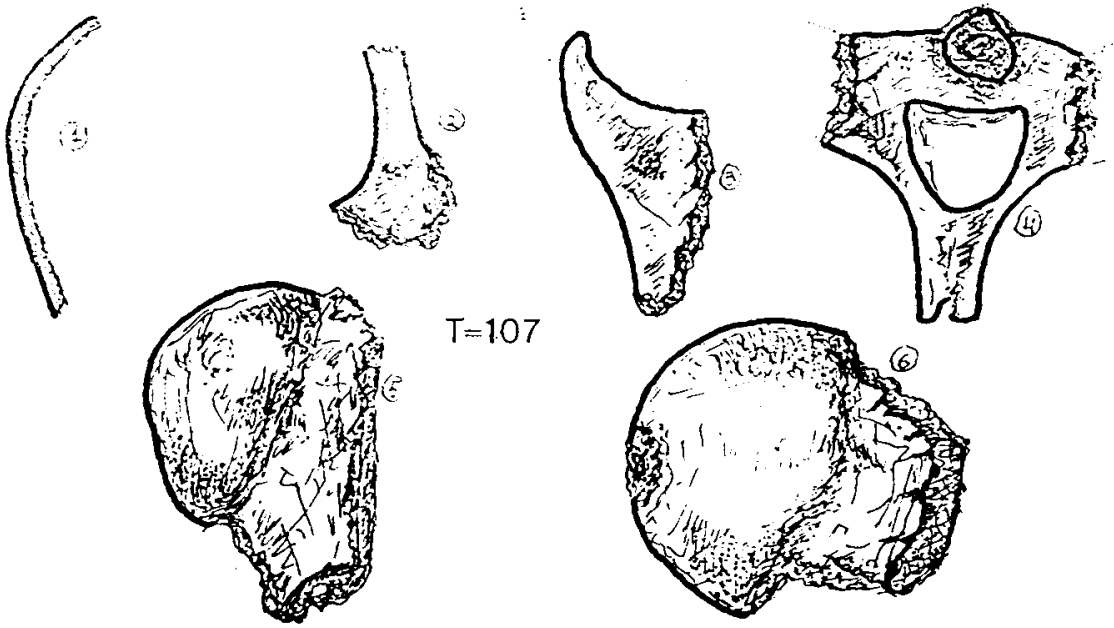

Fig. 5.

T. 118. En el inventario de tumbas se describen dos tumbas, $118 \mathrm{y}$ 118'. La urna con los restos óseos estaban solamente en la primera, en la bis sólo un resto cerámico. Examen anatómico de los restos óseos: 106 fragmentos y esquirlas. CRÁNEO: un conjunto de láminas craneales de lactante. Grosores de 2-4 mm. Otro conjunto de láminas craneales y suturas sin soldar, de pequeños dentellones. Grosores de 5 a $7 \mathrm{~mm}$. Una apófisis mastoides de pequeño volumen (1). Fragmento occipital con grosor de protuberancia de $11 \mathrm{~mm}$ y líneas nucales de inserción muscular acusadas. Malar, con reborde orbital fino y órbita pequeña ? Maxilares derechos-izquierdos con parte de arcada y restos alveolares de I-I-C-P de dientes permanentes (3). Paladar incompleto (3). Mandíbula con mentón poco prominente, parte de arcada con alveólos de I-I-C-P derechos (4), que se articula con la porción del maxilar. VÉRTEBRAS: cinco cuerpos de vértebras dorsales, bordes con "sindesmofitos" grandes que se corresponden. Diámetros (sólo medidas en 4):

\section{Carillas superiores}

$25 \times 23 \mathrm{~mm}=92$

$28 \times 26 \mathrm{~mm}=92,8$

$31 \times 30 \mathrm{~mm}=96,7$

$34 \times 32 \mathrm{~mm}=94,1$

\section{Carillas inferiores}

$32 \times 32 \mathrm{~mm}=100$

$34 \times 32 \mathrm{~mm}=44,1 \quad 19 \mathrm{~mm}$

$34 \times 32 \mathrm{~mm}=94,1 \quad 20 \mathrm{~mm}$

$35 \times 30 \mathrm{~mm}=35,7 \quad 21 \mathrm{~mm}$

Altura total calculada para esta serie: $95 \mathrm{~mm}$ ? Cinco cuerpos de vértebras lumbares, deformados pero que se corresponden, en la cara inferior de 


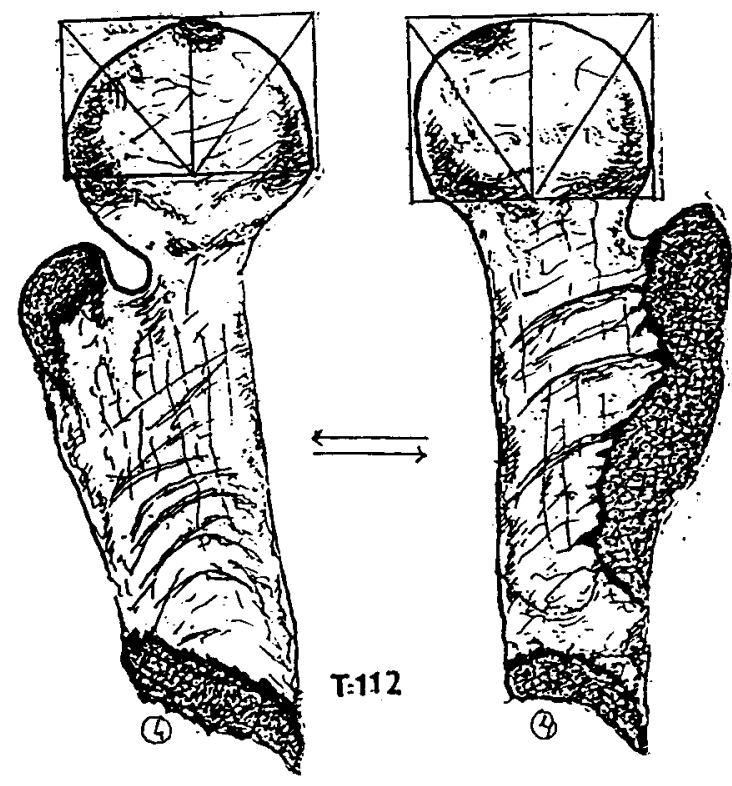

Fig. 6 .

la 2. " un gran «sindesmofito" homólogo al de la cara superior de la 3." Diámetro en la más completa: superior, $23 \times 46 \mathrm{~mm}$; índice, 50 ; y en otra, $33 \times 49 \mathrm{~mm}$; índice, 67,3. Altura total calculada para la serie completa, $137 \mathrm{~mm}$ ? Sacro, fragmentos con las vertebras soldadas. EXTREMIDADES: polifracturación intensa, estrías lineales, concéntricas y semilunas. Muy calcificada, “eburneación». Clavícula derecha, diámetro 11 × $12 \mathrm{~mm}$. Perímetro, $37 \mathrm{~mm}$. Omóplato, fosa glenoidea de $27 \times 38 \mathrm{~mm}$. Índice, 71 . Fragmento de pelvis, espina ilíaca soldada. Cabeza de fémur incompleta, diámetro en diáfisis $19 \times 21 \mathrm{~mm}$. Grosores de 6 a $8 \mathrm{~mm}$. Tibia, diámetros en diáfisis $17 \times 22 \mathrm{~mm}$. Calcáneo incompleto, osificado, de buen tamaño. Alto, $45 \mathrm{~mm}$. Ancho, $35 \mathrm{~mm}$. Metatarsiano, longitud $75 \mathrm{~mm}$. Restos Oseos Animales (ROA).

Resumen: restos craneales de un niño ilactante? y restos de un individuo de naturaleza grácil, adulto, entre 20 y 25 años, alofixo, que por el ajuar de armas (falcata, lanza, escudo) consideramos varón. Queda en interrogante si se trata de una tumba doble, dada la escasez de restos del infante, si bien estaban todos los restos mezclados en una sola urna.

T. 119. Examen de los restos óseos: 27 fragmentos y esquirlas. CRÁNEO: láminas soldadas. Grosores de 7-7 mm. EXTREMIDADES: intensa polifracturación lineal y en pico de flauta. Porción de cabeza de fémur 

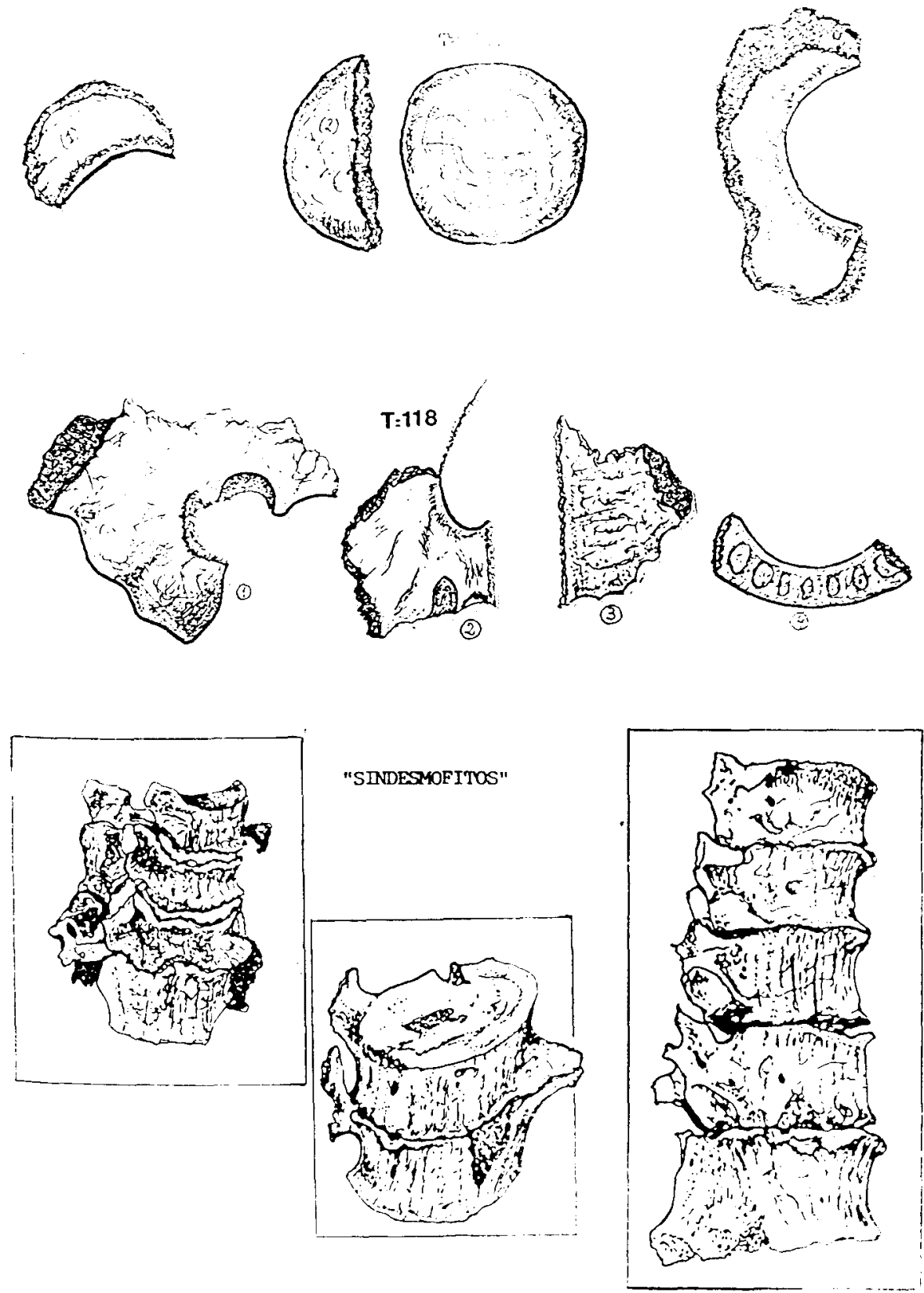

Fig. 7. 
derecho (1)-izquierdo (2), diámetros, 38 y $39 \mathrm{~mm}$; alturas, 28 y $29 \mathrm{~mm}$. Trocánter menor y línea intertrocantérea de buen desarrollo. Un cuerpo de vértebra lumbar, incompleto, diámetro, $39 \times 40$ ?; altura, $29 \mathrm{~mm}$. Índice, 97,5 .

Resumen: individuo varón mayor de 20 años. En el ajuar: falcata, escudo y lanza. Fíbula, fusayola y anillo

T. 122. Examen de los restos óseos: 32 fragmentos y esquirlas. VÉRTEBRAS: partes de cuerpos de vértebras lumbares. Soldaduras a término. Diámetro de una carilla superior, $27 \times 35 \mathrm{~mm}$. Altura, $22 \mathrm{~mm}$. ? Índice, 77,1. EXTREMIDADES: fragmentos de metacarpianos, deformes, soldadura a término. Parte de epífisis superior retraída, estallada. Trocánter menor y crestas de inserción desarrollados. Diámetros de diáfisis $24 \times 25 \mathrm{~mm}$. Tibia, partes de diáfisis de buen desarrollo y fuerte maleólo interno.

Resumen: individuo anatómicamente varón, mayor de 20 años, pero con un ajuar típicamente femenino (agujón hueso para el pelo, anillos, lámina de hueso labrada, alfiler, fusayolas), por tanto, hembra fornida. Viril.

T. 123. Examen anatómico de los restos óseos: 36 fragmentos y esquirlas. CRÁNEO: mandíbula fragmentada con el cóndilo derecho (1) . Mide $8 \times 16$. Índice, 50 . VÉRTEBRAS: tres cuerpos de vértebras dorsales. Diámetro anterior-posterior, $30 \mathrm{~mm}$. Altura, $27 \mathrm{~mm}$. En otros dos cuerpos de vértebras lumbares. Diámetros, $29 \times 41 \mathrm{~mm}$. Alturas, 26 y $27 \mathrm{~mm}$. Índice, 70,7. EXTREMIDADES: omóplato, cavidad glenoidea (2) de $26 \times$ 36. Índice, 72. Cabeza de húmero (3), soldadura a término, en diáfisis, diámetro, $26 \mathrm{~mm}$. Fragmento de la epífisis inferior (4), mide transverso máximo, $60 \mathrm{~mm}$. En la parte articular: transverso máximo, $40 \mathrm{~mm}$. Cóndilo radial, $18 \times 19 \mathrm{~mm}$. Fosa olecraniana, ancho, $26 \mathrm{~mm}$. Diámetro anteroposterior, $26 \mathrm{~mm}$, fondo perforado. Fragmento del cúbito izquierdo curvado, cuarteado, en lineales y semilunares. Olécranon roto, altura, $22 \mathrm{~mm}$ ??. Diáfisis, $12 \times 14 \mathrm{~mm}$. Fragmento de radio, cabeza de $22 \mathrm{~mm}$. Fragmento del coxal ilíaco, escotadura ciática abierta, redondeada y cavidad cotiloidea concuerda con la cabeza femoral, cuyos diámetros son: derecha, 43 x 44; izquierda, $42 \times 44$. Alturas, 26 y $27 \mathrm{~mm}$. Fragmento de tibia izquierda, con el maleólo de buen tamaño. Cavidad articular astragalina, $24 \times 29 \mathrm{~mm}$ ?? Calcáneo deformado, retraído, largo total sobre $50 \mathrm{~mm}$ y fragmentos de metatarsianos, osificados, largos sobre $60 \mathrm{~mm}$.

Resumen: individuo adulto, varón. Su ajuar: falcata, lanza, escudo y vasitos tocador, fíbula, anillos, agujón de hueso por tanto un ejemplo de ajuar dual y, sin dudas, anatómicas. 

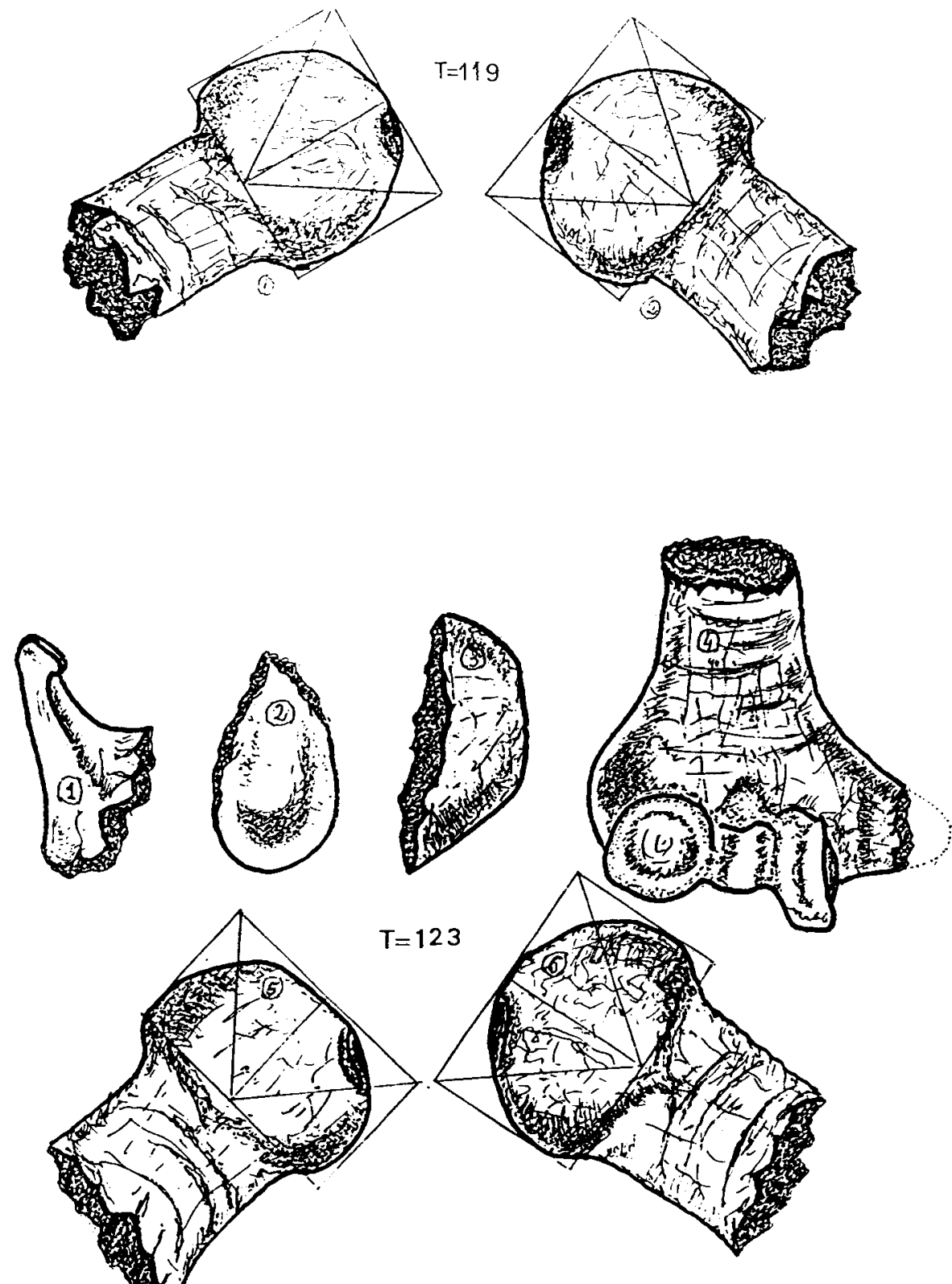

Fig. 8. 
T. 125-A Examen anatómico de los restos óseos: 33 fragmentos y esquirlas. CRÁNEO: frontal, borde orbitario fino. Temporales, en uno un peñasco de poco volumen, en otro apófisis mastoides plana, de poco volumen. Maxilar derecho con parte del borde alveolar de molares y el de $M 3$ aún ocluido. TÓRAX: fragmento de mango esternal, poco robusto. VÉRTEBRAS: axis (3) deformado. Diámetro transverso total sobre $59 \mathrm{~mm}$ y del canal raquídeo, $25 \mathrm{~mm}$. Altura total sobre $36 \mathrm{~mm}$. En otra vértebra cervical diámetros de la carilla superior, $15 \times 18 \mathrm{~mm}$; de la inferior, $18 \times$ $32 \mathrm{~mm}$. En vértebra dorsal, deformada, diámetros: carilla superior, $31 \times$ $18 \mathrm{~mm}$; inferior, $25 \times 20 \mathrm{~mm}$ ?? Tres cuerpos de vértebras lumbares (4), deformados, diámetros: carilla superior, $28 \times 45 \mathrm{~mm}$ ??; inferior, $19 \times 25$ $\mathrm{mm}$. Alturas sobre $24-25 \mathrm{~mm}$. En una de ellas se aprecia en su pedículo derecho una deformidad y engrosamiento con apófisis articulares de gran tamaño, deformes por callosidades, iacción del calor?, ipatológicas? y en otro cuerpo "sindesmofitos" grandes en ambas carillas, que tienen los siguientes diámetros: superior, $31 \times 47 \mathrm{~mm}$; índice 65,9; e inferior, $31 \times$ 51 y alturas de $24 \mathrm{~mm}$. Fragmento de sacro, deformado, retracción, iniciada soldadura entre primera y segunda vértebra. Longitud máxima, 125 ? Canal raquídeo, $28 \mathrm{~mm}$. Altura de primera en cara anterior, $30 \mathrm{~mm}$; en posterior, $25 \mathrm{~mm}$. En la segunda anterior, 26 y posterior, $19 \mathrm{~mm}$, teniendo como base estas medidas supondría calcular la total para el sacro sobre $112 \mathrm{~mm}$. Sacro homobasal, de curvadura rectilínea, caracteres femeninos. EXTREMIDADES: fragmento de coxal, cavidad cotiloidea incompleta (2) medidas sobre $40 \times 48 \mathrm{~mm}$ y bola articular o cabeza de fémur (1-2), diámetros de $41 \times 45 \mathrm{~mm}$. Altura, $45 \mathrm{~mm}$.

Resumen: individuo anatómicamente hembra sobre 18 años (ver final de la tumba siguiente).

T. 125-B Examen anatómico de los restos óseos: 54 fragmentos y esquirlas. CRÁNEO: parietales, cuarteados, con estrías semilunas, dentellones de tamaño medio, sinostosis iniciada en cara interna. Grosores de 5 a $8 \mathrm{~mm}$. Mandíbula, solo cóndilo derecho, de $8 \times 18 \mathrm{~mm}$. Índice, 44,44. VÉRTEBRAS: cuatro cuerpos de vértebras cervicales, deformes, con la apófisis y ganchos de volumen mayor al normal. Su aspecto general evoca el de una sustancia cérea sometida a una gran temperatura, derretida en goteos, aspecto patológico que se corresponde con el de vértebras deformadas por "sindesmofitos" y "osteofitos" en toda la columna vertebral. Estos cuatro cuerpos vertebrales podrían ser de $3 .^{a}$ a $6 .^{a}$ y sus medidas: en carilla superior-interganchos de $12 \times 18 \mathrm{~mm}$ y posterior de 11 a $12 \mathrm{~mm}$. Altura total calculada de las cuatro, $155 \mathrm{~mm}$. Cinco cuerpos de vértebras lumbares, deformados, incompletos, con "sindesmofitos", «picos de loro" en avanzado grado de soldadura. Medidas: 

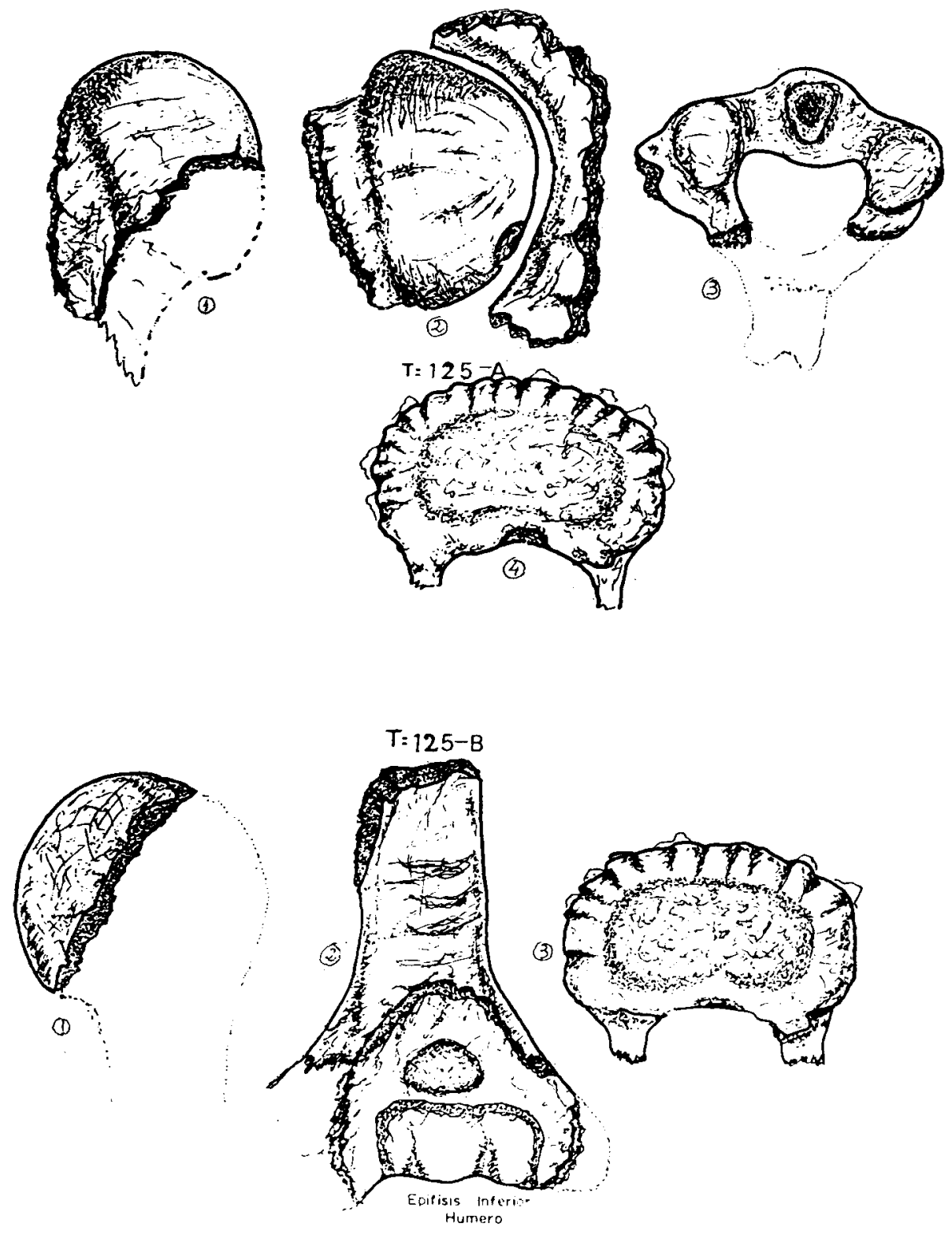

Fig. 9. 
Carilla superior

1. ${ }^{\mathrm{a}} 26 \times 40 \mathrm{~mm}=65$

2. ${ }^{\mathrm{a}} 28 \times 41 \mathrm{~mm}=68,2$

3. $29 \times 46 \mathrm{~mm}=63$

4 . $^{\mathrm{a}} 30 \times 50 \mathrm{~mm}=60$

5. ${ }^{2} 35 \times 45 \mathrm{~mm}=77,7$
Carilla inferior Altura

$28 \times 41 \mathrm{~mm} 22 \mathrm{~mm}$

??

$30 \times 48 \mathrm{~mm}$

$30 \times 51 \mathrm{~mm}$

$33 \times 51 \mathrm{~mm}$
$25 \mathrm{~mm}$ ?

$25 \mathrm{~mm}$

$25 \mathrm{~mm}$

$25 \mathrm{~mm}$
Canal raquídeo

$18 \times$ ?? $\mathrm{mm}$

$11 \times 18 \mathrm{~mm}$

??-

$20 \times$ ??

$20 \times 23 \mathrm{~mm}$

alturas de los pedículos entre 12 y $14 \mathrm{~mm}$. La altural total calculada para esta serie completa lumbar sería de unos $122 \mathrm{~mm}$. EXTREMIDADES: cabeza de húmero (1), diámetro sobre $42 \mathrm{~mm}$ ? En la epífisis inferior, fosita olecraniana no perforada, diámetro de la troclea, $18 \mathrm{~mm}$ (2). VÉRTEBRAS: La intensa fracturación no permita medidas, presentan en general un aspecto compacto y grueso, con estrías lineales, concéntricas y semilunares. ROA.

Resumen: individuo anatómicamente varón, corpulento, mayor de 25 años.

NOTA: En el libro, D. Emeterio Cuadrado sólo menciona una tumba 125 con ajuar de armas y una sola urna y una concomitancia con las tumbas 128 y 129 de posibles varones por su ajuar y anatomía. Estos dos «paquetes" óseos 125-A y 125-B, individualizados claramente por el excavador, también lo están por su anatomía, el A como hembra o varón grácil, y el B varón robusto y de mayor edad, con lo que se plantea el problema de las tumbas dobles, difícil interrogación, que sólo se podría contestar con el análisis de la contemporaneidad de las muertes, por ejemplo, co la concentración de fluor, por otra parte difícil de interpretar en estos casos. Otra interpretación de este caso podría ser: Se trata de un enterramiento simultáneo doble de un padre y de un hijo varón, grácil, o de varón y hembra ???. Lo cierto es que la tumba sólo tiene una urna y existen dos «paquetes» con restos óseos bien separados anatómicamente y un ajuar de armas y algo de adornos.

T. 126. Destruida y concomitante con la 125, sin ajuar ni cerámicas, lo que contribuye a la confusión.

T. 127. Examen anatómico de los restos óseos: 80 fragmentos y esquirlas. CRÁNEO: parietales, láminas en vías de soldadura. Grosores, 4$6 \mathrm{~mm}$. Occipital, negruzco, grosores de 6 a $9 \mathrm{~mm}$. Inión y crestas musculares poco desarrolladas. Mandíbula, fragmento con parte del alvéolo M3. VÉRTEBRAS: cuerpo de vértebra dorsal, carillas soldadas. Altura, $19 \mathrm{~mm}$ y diámetros, $22 \times 20 \mathrm{~mm}$. Índice, 90,9. EXTREMIDADES: húmero, fragmentos de diáfisis, ennegrecidos. Diámetro a nivel de agüjero nutricio, $20 \times 22 \mathrm{~mm}$. Cúbito, epífisis inferiores con restos de apófisis coronoides 
izquierdos. Soldaduras a término. Altura del olécranon, $33 \mathrm{~mm}$. Carilla articular, $24 \times 18 \mathrm{~mm}$. Diámetro, $17 \mathrm{~mm}$. Escafoides izquierdos. Largo, $29 \mathrm{~mm}$. Ancho, $14 \mathrm{~mm}$. Negruzco. Pelvis fragmentada con resto de cavidad cotiloidea, aparenta un tamaño medio, osificada. Restos ennegrecidos, carbonizados, estrías lineales y semilunas, de poco espesor y diámetros medios. ROA.

Resumen: individuo anatómicamente varón sobre 20 años. Ajuar: armas, fíbula y pinzas. Restos de esculturas. Cerámica abundante.

T. 128. Examen anatómico de los restos óseos: 110 fragmentos y esquirlas. CRÁNEO: frontal, reborde orbitario grueso, gran escotadura supraorbital. Glabela desarrollada; grosor, $16 \mathrm{~mm}$. Parietales, suturas sin soldar, láminas soldadas. Grosores, 4 a $5 \mathrm{~mm}$. Temporal derecho, arranque de apófisis zigomática grueso. Cavidad glenoidea de $14 \mathrm{~mm}$. Crestas de inserciōn muscular desarrolladas. Malar apófisis ascendente fuerte y grueso reborde orbital, impresión de órbita grande. VÉRTEBRAS: restos de apófisis espinosas, deformes, una muy voluminosa patológica. Cuerpos de vértebras dorsales, carillas osificadas y con "sindesmofitos"; diámetros, $35 \times 30 \mathrm{~mm}$; alturas, de 22 a $26 \mathrm{~mm}$ ? Sacro, con primera vértebra que parece sin soldar a segunda, lo que data la edad. EXTREMIDADES: polifracturación intensa. Fragmento de bola de férmur.

Resumen: individuo anatómicamente varón, robusto, sobre 20 años. Ajuar: armas (dos falcatas, escudo, lanza, cuchillo, fíbula y anillo).

T. 129. Es otra de las concomitantes con la 125, como la anterior, en la que se localizaron dos lotes de armas y no se han analizado restos óseos. Ajuar: dos falcatas, dos escudos, dos lanzas. Cerámicas abundantes, ib/atc/B.R... Fíbula, fusayola, hebilla bronce. Ajuar rico de varón (se plantea la duda de si estarán mezclados).

T. 130. Examen anatómico de los restos óseos: 47 fragmentos y esquirlas. CRÁNEO: fragmentos negruzcos, brillantes, superficies lisas, sin estrías ni retracciones. Láminas sin soldar, al igual que las suturas y grosores de 4 a $9 \mathrm{~mm}$. Temporal, con parte del peñasco y mastoides, de poco tamaño. VÉRTEBRAS: cuerpo de vértebra dorsal; diámetros carilla superior, $24 \times 23 \mathrm{~mm}$; carilla inferior, $31 \times 24 \mathrm{~mm}$. Altura, $18 \mathrm{~mm}$ ?. Índice, 85,8. EXTREMIDADES: Polifracturación, con estrías lineales y en pico de flauta, superficies carbonizadas. Omóplato, cavidad glenoidea derecha, ??; izquierda, $23 \times 27 \mathrm{~mm}$. Índice, 95. Soldadura a término. Húmero, cabeza que se corresponde con la cavidad glenoidea. Coxal y borde ilíaco soldado. Fragmentos de diáfisis femorales sobre $25 \mathrm{~mm}$ de diámetro y tibiales de $20 \times 17 \mathrm{~mm}$. ROA. 
Resumen: individuo anatómicamente hembra, sobre 20-25 años. Ajuar: adornos (fusayolas, conchas, dos fíbulas, anillo, lámina de hueso labrada, cadena, cerámicas).

T. 131. Examen anatómico de los restos óseos: 92 fragmentos y esquirlas. CRÁNEO: superficies lisas, ennegrecidas, brillantes. Frontal, reborde orbital fino. Parietal derecho. Sutura de dentellones pequeños, sin soldar. De la sagital $50 \mathrm{~mm}$ de partes de $S / 1$ y $S / 2$ y de la coronal, $19 \mathrm{~mm}$. Grosores, 7 a $8 \mathrm{~mm}$. Occipital, dentellones grandes, sin soldar, protuberancia ósea exterior de poco volumen y crestas de inserción muscular poco acusadas. Grosores de 3 a $7 \mathrm{~mm}$ y en inión de $10 \mathrm{~mm}$. Fuerte retracción, "eburneación» y semilunas. Esfenoides, con la apófisis Pterigoides, que no presenta señales del fuego. Malar izquierdo, parte del reborde orbital, filo. Maxilar izquierdo borde alveolar de P.P y M1, desprendidos post mortem abiertos y de $M 2$ y $M 3$, éste sin emerger. Mandíbula, rama ascendente derecha, cresta del maxilar masetero poco acusada y en otro fragmento de borde alveolar izquierdo, alvéolos de P-PM1, que se corresponden con los del maxilar. Otro fragmento con el cóndilo derecho (1). Mide $9 \times 17 \mathrm{~mm}$. Índice, 52,9. VÉRTEBRAS: cuerpos de seis vértebras cerviales. Axis (2) o 2. ${ }^{a}$ de pequeño tamaño, incompleta, altura calculada, $18 \mathrm{~mm}$ ?? En los otros cuerpos, que se articulan entre sí, aunque deformes y con retracciones se obtienen las medidas:

\begin{tabular}{llllll} 
Carilla superior & Carilla inferior & Altura & \multicolumn{2}{c}{ Canal raquídeo } \\
& & & & \\
$2 .^{\mathrm{a}}$ & $15 \times 22 \mathrm{~mm}$ & $? ? \times ? ?$ & $? ?$ & $13 \times 18 \mathrm{~mm}$ & 68,1 \\
$3^{\mathrm{a}}$ & $? ? \times ? ?$ & $15 \times 22 \mathrm{~mm}$ & $11 \mathrm{~mm}$ & $13 \times 18 \mathrm{~mm}$ & \\
$4 .^{\mathrm{a}} 11 \times 20 \mathrm{~mm}$ & $? ? \times ? ?$ & $15 \mathrm{~mm}$ & $13 \times 18 \mathrm{~mm}$ & 55 \\
$5 .^{\mathrm{a}}$ & $11 \times 20 \mathrm{~mm}$ & $? ? \times ? ?$ & $11 \mathrm{~mm}$ & $13 \times 18 \mathrm{~mm}$ & \\
$6^{\mathrm{a}}$ & $10 \times 19 \mathrm{~mm}$ & $? ? \times ? ?$ & $11 \mathrm{~mm}$ & $13 \times 18 \mathrm{~mm}$ & 52,6 \\
$7^{\mathrm{a}}$ & $10 \times 19 \mathrm{~mm}$ & $? ? \times ? ?$ & $11 \mathrm{~mm}$ & $13 \times 18 \mathrm{~mm}$ &
\end{tabular}

Altura total calculada para la serie, $70 \mathrm{~mm}$.

Fragmento de un cuerpo de vértebra dorsal, soldadas las carillas y de $21 \times 21 \mathrm{~mm}$ la superior, inferior ?? y altura, $16 \mathrm{~mm}$. Fragmentos de tres cuerpos de vértebras lumbares, carillas soldadas a término. Medidas: en una carilla superior, $23 \times 34 \mathrm{~mm}$; en las otras, $24 \times 36 \mathrm{~mm}$ y $26 \times 38 \mathrm{~mm}$. Canal raquídeo, $14 \times 18 \mathrm{~mm}$ y $16 \times 20 \mathrm{~mm}$. Sacro, primera vértebra sin soldar a la segunda. Data edad. EXTREMIDADES: clavícula derecha, largo total calculado, 80-90 mm. Perímetro, $23 \mathrm{~mm}$. Diámetro, $9 \times 6 \mathrm{~mm}$. Índice, 66.6. Húmero, cabeza o epífisis superior muy deformada. Diámetro en diáfisis, $17 \times 14 \mathrm{~mm}$. Porción de la trócleo de $19 \times 10 \mathrm{~mm}$. Fémur, cabeza muy deformada (4). Diámetro transversal $24-35 \mathrm{~mm}$ ? Fragmento izquierdo 

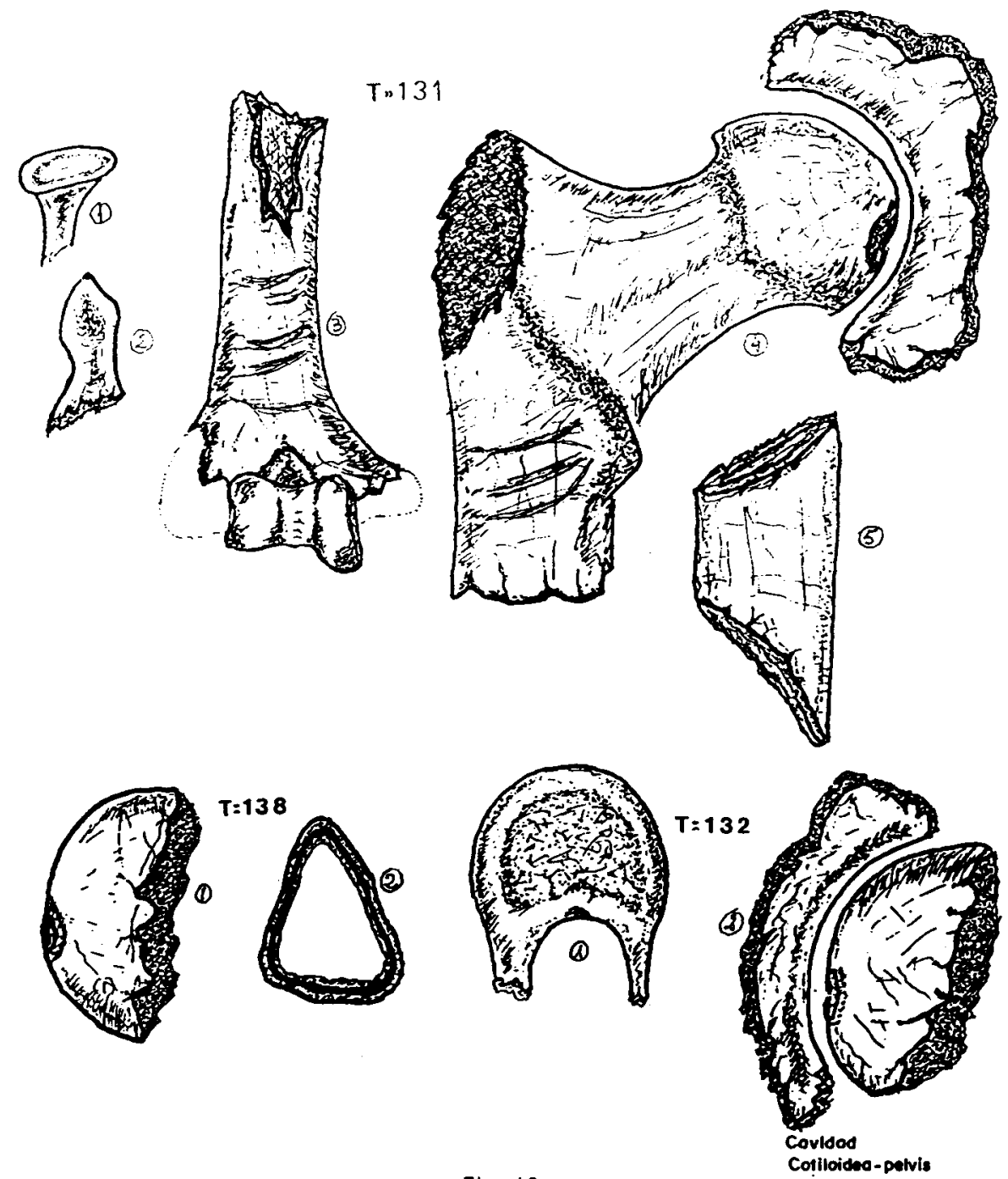

Fig. 10. 
concordante con el anterior, medidas: largo total de cabeza al arranque del cuello, $75 \mathrm{~mm}$, y desde la línea intertrocantérea a cabeza, $36 \mathrm{~mm}$. Diámetro del cuelo, $22 \times 17 \mathrm{~mm}$. Distancia de trocánter mayor o menor, $64 \mathrm{~mm}$. Diámetro bajo el trocánter menor, $25 \times 19 \mathrm{~mm}$, y en la parte media (?) (5), $22 \times 18 \mathrm{~mm}$. Fuertes retracciones y fracturas en los fragmentos (5) calcinados y de menor intensidad en los ennegrecidos, carbonizados, que la presentan lisas, tres metatarsianos muy fracturados. ROA.

Resumen: individuo anatómicamente hembra, juvenil, entre 16-18 años. Ajuar de escasa cerámicas, un anillo con una falange incluida. Fusayola.

T. 132. Examen anatómico de los restos óseos: 80 fragmentos y esquirlas. CRÁNEO: frontal, un fragmento de borde orbital, acusado. Seno frontal grande. Grosores de 3 a $9 \mathrm{~mm}$. Láminas sin soldar. Sutural coronal de pequeños dentellones. Sinóstosis iniciada en cara interna. Occipital, se aprecian perfectamente seno y fosas cerebelosas y cerebral. Grosores, 3 a $7 \mathrm{~mm}$, muy calcinados, blancuzcos. TÓRAX: fragmentos de costillas, poco robustas y mango de esternón muy calcinado y retraído. VÉRTEBRAS: fragmentos de vértebras dorsales (1). Alturas en cuerpos, 1-23 $\mathrm{mm}$. Fragmento primera vértebra sacro soldada a segunda. Carilla superior, 27 $\times 40 \mathrm{~mm}$. EXTREMIDADES: omóplato, parte de la cavidad glenoidea, ancho, 20? Húmero, epífisis inferior. Diámetro transverso total, $37 \mathrm{~mm}$. ? Tróclea, anteroposterior, $13 \mathrm{~mm}$. Soldadura a término. Fémur, cabeza incompleta (2), diámetro ?39-40 mm. ? Soldadura a término. Ídem en la meseta tibial. Fragmento astrágalo derecho.

Resumen: individuo anatómicamente alofixo, hembra o varón grácil. Mayor de 20 años. Ajuar con falcata, lanza, escudo, fíbula, por tanto, varón.

T. 133. Examen anatómico de los restos óseos: 59 fragmentos y esquirlas. CRÁNEO: solamente esquirlas de láminas sin soldar. VÉRTEBRAS: fragmentos de cuerpos de vértebras dorsales, alturas entre 21-23 mm. EXTREMIDADES: superficies cuarteadas, estrías y semilunas, epífisis aplastadas. Omóplato, cavidad glenoidea, $31 \times 28 \mathrm{~mm}$. Índice, 90 . Húmero, partes de bola articular derecha e izquierda.

Resumen: Individuo anatómicamente alofixo. Por el ajuar, hembra (fusayolas, fíbula, agujón de hueso, pinzas, anillo).

T. 136. Examen anatómico de los restos óseos: 50 fragmentos y esquirlas. CRÁNEO: fragmentos muy pequeños. Suturas soldadas. Grosores de 4-6 mm. EXTREMIDADES: polifracturación intensa. Láminas gruesas y bien calcificadas. Radio, cabeza, diámetro, $18 \mathrm{~mm}$. ROA. 
Resumen: individuo anatómicamente adulto, alofixo. Por el ajuar varón (falcata, escudo, lanza, fíbula hierro).

T. 138. Túmulo muy importante, de tres escalones y torrecilla. Examen anatómico de los restos óseos: 201 fragmentos y esquirlas. CRÁNEO: láminas y suturas sin soldar en cara externa, iniciada en cara interna temporoparietal. Grosores, $4 \mathrm{~mm}$. Tempora, peñasco derecho terminando de soldar, tamaño medio. Occipital, restos con el cóndilo izquierdo de tamaño medio. Malar izquierdo, acusado reborde orbital. Mandíbula, cóndilo derecho, de $12 \times 6 \mathrm{~mm}$. Índice, 50. TÓRAX: fragmentos de costillas, sin soldar las carillas articulares. EXTREMIDADES: polifracturación intensa. Omóplato, cavidad glenoidea de $33 \times 26 \mathrm{~mm}$. Índice, 78,7. Húmero, cabezas incompletas, soldadura a término. Fémur, cabeza incompleta (1), diámetro, ?42 mm. Epífisis inferior con maléolo izquierdo desarrollado. Soldaduras a término. Tibia, epífisis soldada, diámetro en diáfisis (2), 26 x $30 \mathrm{~mm}$. Astrágalos incompletos, tróclea de $32 \times 32 \mathrm{~mm}$ y metarsianos soldados.

Resumen: individuo anatómicamente adulto joven, menor de 20 años, varón. Por el ajuar varón (falcata, lanza, escudo, soliferrum, fíbulas, hebillas, pinzas).

T. 139. Examen anatómico de los restos óseos: 85 fragmentos y esquirlas. CRÁNEO: láminas sin soldar, iniciada en cara interna. Grosores, 4 a $6 \mathrm{~mm}$. VÉRTEBRAS: en vértebras dorsales alturas sobre $12 \mathrm{~mm}$. En vértebras lumbares alturas sobre $28 \mathrm{~mm}$. En uno, diámetro, $26 \times 42 \mathrm{~mm}$. Índice, 61,9. EXTREMIDADES: polifracturación intensa, lineales, semilunas y picos de flauta. Omóplato, cavidad glenoidea (3) de $30 \mathrm{~mm}$ de altura. Húmero, cabeza incompleta (2); diámetro, $33 \mathrm{~mm}$. En diáfisis $15 \times 17 \mathrm{~mm}$ de diámetro. Fragmentos de metacarpianos. Soldadura a término en todas las epífisis. Coxal, parte de cavidad cotiloidea $40 \mathrm{~mm}$ diámetro transverso. Fémur, cabeza o bola, diámetro calculado $40-45 \mathrm{~mm}$ (43).

Resumen: individuo anatómicamente alofixo, menor de 20 años. Ajuar de hembra (dos fusayolas, colgante vítreo y anillo).

T. 140. Examen anatómico de los restos óseos: 235 fragmentos y esquirlas. CRÁNEO: se identifican fragmentos y esquirlas de un infante. Sólo láminas o cascarillas de huesos craneales. Otros fragmentos y esquirlas con partes de sutura craneal de dentellones finos, sin soldar en general, pues en alguno está iniciada en cara interna. Frontal, glabela redondeada de poco volumen, $9 \mathrm{~mm}$ de grosor. Temporales, una cavidad glenoidea pequeña e igual el resto de la mastoides. Peñascos soldados. Maxilar derecho en borde alveolar restos de los de I-I-P-P y parte de paladar de $22 \times 18 \mathrm{~mm}$ ?? Índice, 81,8? Molares emergiendo. Fragmento 

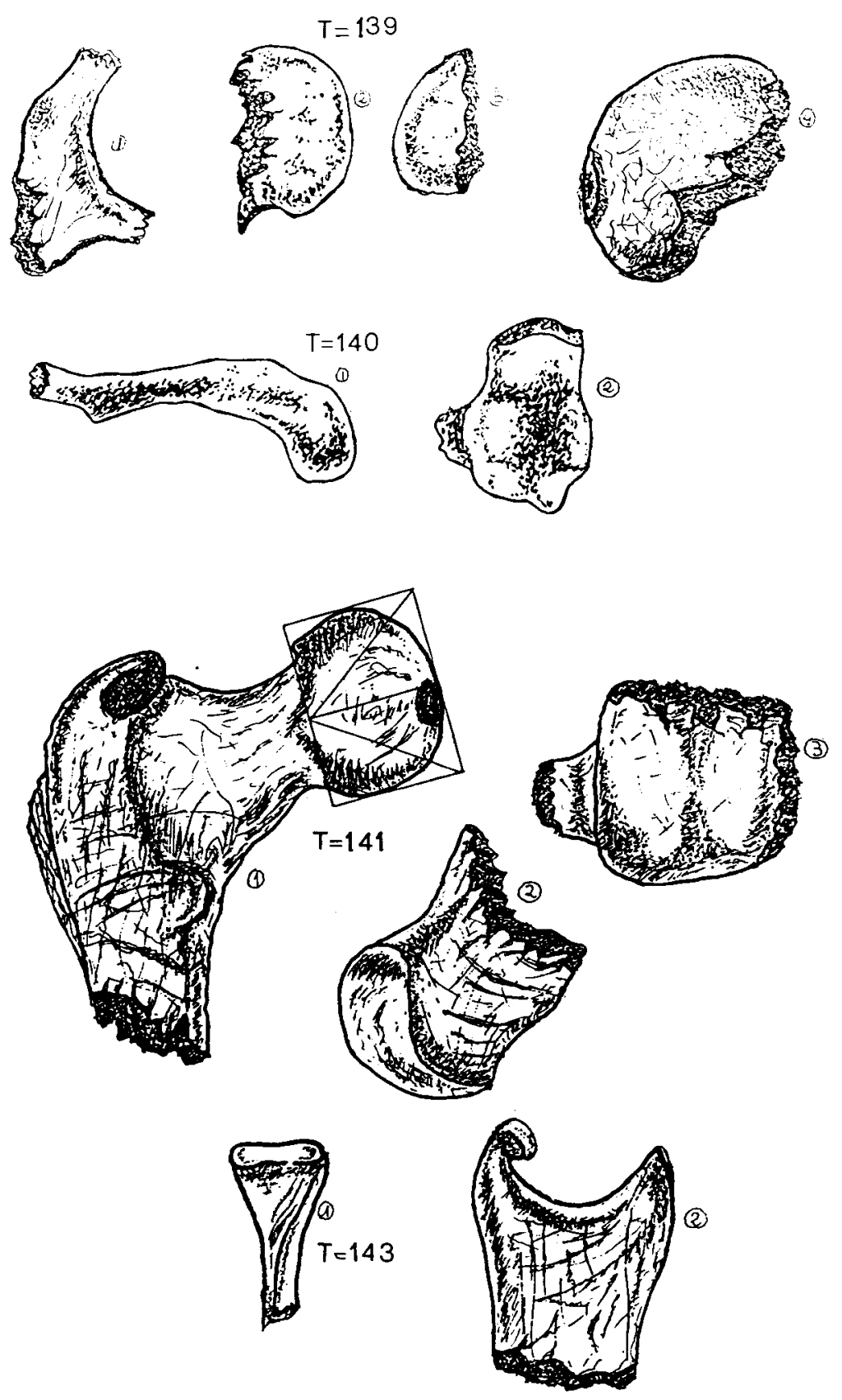

Fig. 11. 
de malar, con reborde orbital fino. Mandíbula, alvéolos de I-I, de dientes permanentes. Alto a nivel de sínfísis, $18 \mathrm{~mm}$. EXTREMIDADES: más de 100 fragmentos y esquirlas que dificultan la identificación, pero, como dato importante, las epífisis en vías de soldar. Clavícula, carilla acromial sin soldar. Diámetro, $6 \mathrm{~mm}$. Perímetro, $17 \mathrm{~mm}$ (1). Cúbito, epífisis inferior sin soldar. Astrágalo (2), incompleto de pequeño tamaño y escafoides y cuboides incompletos.

Resumen: Urna con restos óseos duales. Los del lactante están sin cremar y los demás corresponden a un individuo joven, sobre 19 años, hembra. Ajuar femenino (el infante sería un neonato, pues en caso de ser fetal estaría cremado) (ajuar con 19 fusayolas, brazalete, piedrecita para colgante, cerámicas).

T. 141. Estudio anatómico de los restos óseos: 67 fragmentos y esquirlas. CRÁNEO: láminas sin soldar, estalladas. Suturas de dentellones pequeños. Grosores de 4 a $8 \mathrm{~mm}$. Frontal, borde orbital fino. Un peñasco de tamaño medio. Mandíbula, cóndilo de $14 \times 16 \mathrm{~mm}$. Índice, 42,85. TóRAX: carillas costales sin soldar. EXTREMIDADES: en omóplatos, carilla glenoidea de $29 \times 16 \mathrm{~mm}$. Índice, 55. Húmero, cabeza incompleta, iniciada soldadura. Epífisis inferior terminando soldadura. Fémur, cabeza izquierda (1) terminando soldadura; diámetro, $36 \mathrm{~mm}$; altura, $18 \mathrm{~mm}$. Parte de un astrágalo (3) y de un calcáneo (2), de tamaño medio.

Resumen: individuo anatómicamente menor de 20 años, hembra. Ajuar: agujón para el pelo, fíbula, pendiente oro, cerámicas.

T. 143. Examen de los restos óseos: 36 fragmentos y esquirlas. CRÁNEO: suturas sinostosadas. Grosores, $8 \mathrm{~mm}$. Mandíbula, cóndilo derecho $(1,2)$ de $18 \times 5 \mathrm{~mm}$. Índice, 27,7. EXTREMIDADES: húmero derecho, fragmentos de diáfisis y epífisis, superficies ennegrecidas, de buen desarrollo y osificación total. Radio, cabeza y cuello con gran tuberosidad bicipital. En cuello, $13 \times 15 \mathrm{~mm}$. Fémur, fuerte línea áspera; grosor, 5$6 \mathrm{~mm}$.

Resumen: individuo anatómicamente varón, adulto mayor de 20 años. Ajuar: cerámica escasa, fusayola, cuchillito, por tanto, ambiguo. En el libro citado de E. Cuadrado dice "no había huesos", como en el caso anterior.

T. 149. Examen anatómico de restos óseos: 32 fragmentos y esquierlas. CRÁNEO: suturas de grandes dentellones, sinóstosis en cara interna. Grosores de 5 a $6 \mathrm{~mm}$. Mandíbula, rama y parte de apófisis coronoides robusta. VÉRTEBRAS: cuerpo de vértebras lumbares, deformados, ennegrecidos; diámetros, 34 × 48 y 35 x $50 \mathrm{~mm}$. Índices, 70,8 y 70 . EXTREMIDADES: polifracturación, superficies negras, estrías lineales y en pico de flauta. Omóplatos, derecho-izquierdo, cavidad glenoidea (3), $31 \times$ 
$25 \mathrm{~mm}$. Índice, 80,6. Cabeza de húmero concordante. Pelvis, fragmento de cabeza femoral concordante, soldadura total; diámetro, ?47 mm. Altura, ?31 mm (2). Índice, 65,9.

Resumen: individuo anatómicamente varón de más de 20 años. Ajuar: armas (falcata, lanza, escudo, fíbula, pendiente oro, torques).

T. 152. Examen anatómico de los restos óseos: 274 fragmentos y esquirlas. CRÁNEO: polifracturación intensa. Grosores de 4 a $6 \mathrm{~mm}$. Láminas soldadas, superficies negras, lisas. Dentellones de tamaño medio, sin soldar. Frontal, reborde orbitario fino, que se articula con el fragmento de malar. Fragmentos de temporales, con arranque de apófisis zigomática de tamaño medio. Cavidad glenoidea en la que se articula el cóndilo del maxilar y conducto auditivo, agujero de $7 \times 16 \mathrm{~mm}$. Maxilares, derecho parte de arcada con alvéolos de I-I-C-P-P-M1-M2 y M1/M2 coronas estalladas, con cierto grado de usura y $M 3$, parece estar emergiendo (data edad). En el izquierdo alvéolos de I-I-C-P-P. Parte del velo del paladar. Ancho de la arcada dental, $35 \mathrm{~mm}$. Mandíbula, parte de rama ascendente con el cóndilo izquierdo de $16 \times 6 \mathrm{~mm}$. Índice, 37,5. Los fragmentos de maxilares y de la mandíbula son concordantes. TÓRAX: cabezas costales osificadas. VÉRTEBRAS: cuerpos y apófisis soldadas. En vértebras dorsales, alturas de cuerpos de 20 a $23 \mathrm{~mm}$. Un cuerpo de vértebra lumbrar; altura, $23 \mathrm{~mm}$. Sacro: en vía de soldadura. EXTREMIDADES: $200 \mathrm{frag}-$ mentos-esquirlas que por su pequeñez plantean dudas de individualización, si bien, en general, me inclino por que toda esta cantidad de restos pertenecen al mismo individuo. Superficies negras, calcinadas y otras blanquecinas, calcificadas, por lo que se presentan toda clase de estríasfractales. Los fragmentos mayores son de: clavícula osificada. Omóplato, cavidad glenoidea incompleta; medidas, ?-18 $27 \mathrm{~mm}$ ?? Húmero, epífisis soldada; diámetro de cabeza articular sobre ?30 × $24 \mathrm{~mm}$. Radio, cabeza osificada, de $18 \mathrm{~mm}$. Pelvis, cresta ilíaca soldada, cavidad cotiloidea concordante con el fragmento de "bola" femoral. Fémur, cabeza o bola incompleta, soldada concordante. Astrágalo, parte trocelar, soldada, de 50 x $25 \mathrm{~mm}$. Metatarsianos, soldados. ROA.

Resumen: individuo anatómicamente sobre más de 20 años, hembra. Ajuar con adornos (agujones del pelo, plaquita de hueso labrada, fíbuilas, caracoles, cuentas vitreas, fusayolas, céramicas).

T. 155. Examen anatómico de los restos óseos: Sólo dientes. Fragmentos de incisivos inferiores permanentes, carbonizados, lo que no permite conclusiones sobre sexo y sobre edad, y sí que no se trata de un lactante. Su ajuar tampoco es demostrativo (botón de cobre, fusayolas (5). Escultura, trozo) ¿Femenino? 

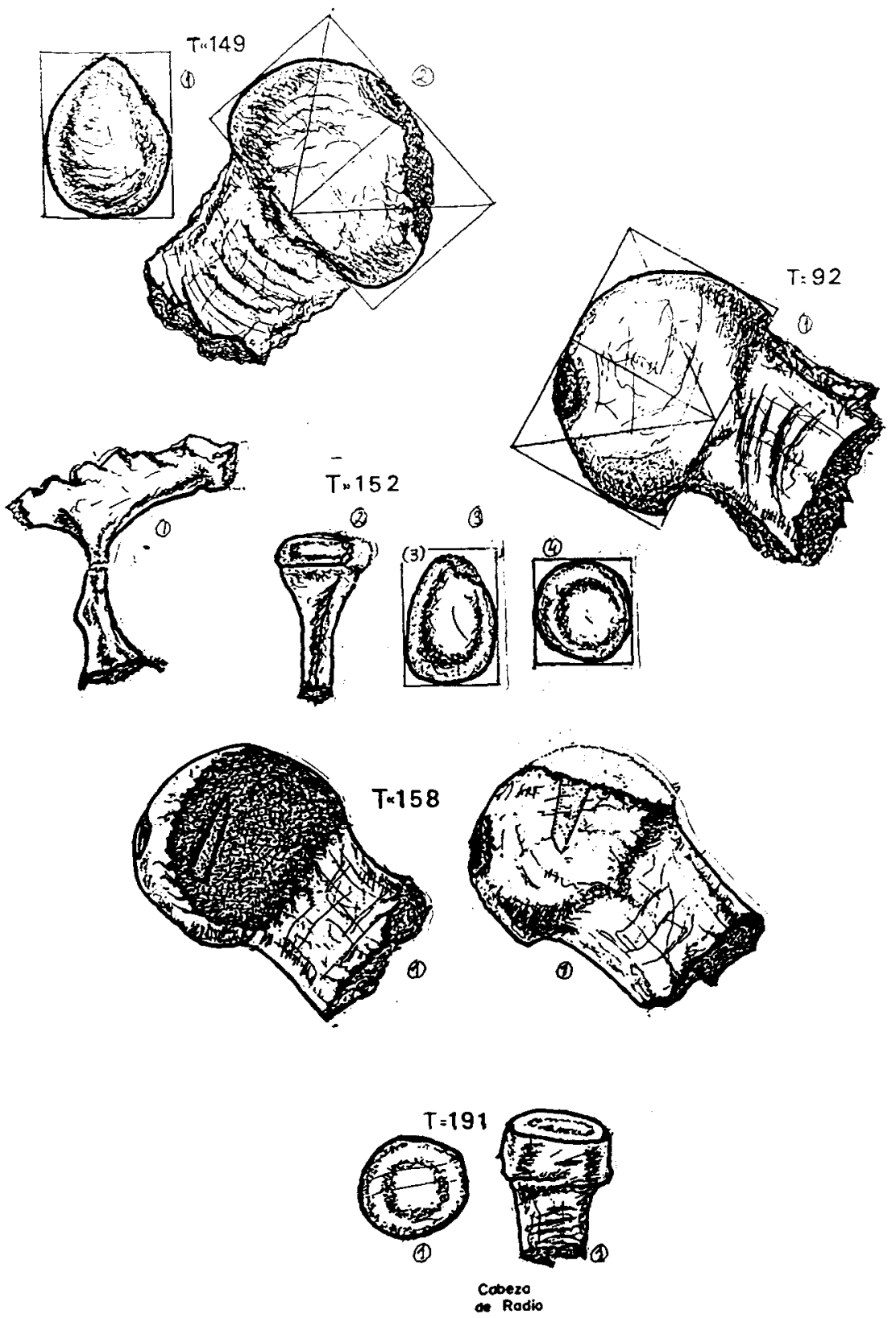

Fig. 12. 
T. 158. Examen anatómico de los restos óseos: 155 fragmentos y esquirlas. CRÁNEO: suturas dentellones pequeños y grandes, sinóstosis iniciada en sagital. Grosores, 3 a $5 \mathrm{~mm}$. Reborde orbital suave, redondeado, al igual que en la apófisis orbital del malar. Fragmento maxilar izquierdo, alvéolos I-I-C-P-P-M1. Bóveda paladar, excavada, profunda. Mandíbula, alvéolos I-I, el segundo desprendido in vivo en vía de reabsorción, los de C-P-P, todos de dientes permanentes. Alto de sínfisis, $21 \mathrm{~mm}$. VÉRTEBRAS: cuerpo de vértebra cervical; altura, $12 \mathrm{~mm}$. Apófisis espinosa séptima grande. Cuerpos de cuatro vértebras dorsales, con «sindesmofitos". Medidas:

$\begin{array}{lllll}\text { Carilla superior } & \text { Carilla inferior } & \text { Altura } & \text { Índice } \\ \text { ?6. }^{\mathrm{a}} 35 \times 28 \mathrm{~mm} & 38 \times 29,5 \mathrm{~mm} & 23 \mathrm{~mm} & 50 \\ ?_{3}^{\mathrm{a}}{ }^{\mathrm{a}} 29 \times 39 \mathrm{~mm} & 29 \times 41 \mathrm{~mm} & 23 \mathrm{~mm} & 74,3 \\ \text { ?4. }^{\mathrm{a}} 29 \times 42 \mathrm{~mm} & 29 \times 41 \mathrm{~mm} & 23 \mathrm{~mm} & 69 \\ \text { ?5. }^{\mathrm{a}} 29 \times 40 \mathrm{~mm} & 35 \times 45 \mathrm{~mm} & 24 \mathrm{~mm} & 72,5\end{array}$

Se podría calcular la altura total de las 12dorsales sobre $330 \mathrm{~mm}$. EXTREMIDADES: polifracturación intensa. Fémur, cabeza o bola articular que presenta una huella penetrante (1), de bordes limpios, algo triangular, semejante a la que podría producir una herida por arma blanca, incisa, ¿falcata-lanza?, por el molde obtenido más bien parece por falcata, in vivo.

Resumen: individuo anatómicamente grácil, alofixo. Por el ajuar, hembra, mayor de 20 años (agujón de pelo, anillos, conchas, fusayolas).

T. 159. Examen anatómico de los restos óseos: 169 fragmentos y esquirlas. CRÁNEO: suturas de dentellones pequeños, sinostosadas. Grosores de 4 a $5 \mathrm{~mm}$. Peñascos izquierdo-derecho grandes, soldados. Malar, reborde orbital redondeado. Maxilar, borde alveolar de I-I-C- P-P-M1M2 y M3. Paladar ancho y profundo. Mandíbula, restos de M3, grande, fuertes crestas de inserción del masetero. TÓRAX: cabezas costales osificadas; altura cuerpos, $13 \mathrm{~mm}$. VÉRTEBRAS: cuerpo de vértebra dorsal; carilla superior, $32 \times 28 \mathrm{~mm}$. Alturas de 18 a $22 \mathrm{~mm}$. Índice, 87,5. EXTREMIDADES: polifracturación intensa. Omóplato, cavidad glenoidea: derecha, $25 \times 30 \mathrm{~mm}$; izquierda, 24,6 × $36 \mathrm{~mm}$. Índice, 68,3. Soldadas. Fémur, línea áspera acusada.

Patología: proceso fistuloso por iquiste dental? a nivel de $\mathrm{M} 1$.

Resumen: Individuo anatómicamente varón, sobre 30 años. Ajuar: armas (falcata, lanza, soliferrum, fíbula). Restos escultóricos.

T. 161 Examen anatómico de los restos óseos: 134 fragmentos y esquirlas. CRÁNEO: suturas dentellones pequeños, sinóstosis de la sagital, 
láminas estalladas. Grosores de 3 a $6 \mathrm{~mm}$. Frontal, borde orbital fino, impresión de órbita pequeña, en lo que incide el fragmento del malar. Mandíbula, ramas de aspecto poco robusto. VÉRTEBRAS: cuerpos de vértebras dorsales; alturas, 19 a $20 \mathrm{~mm}$. Una carilla superior, $32 \times 38 \mathrm{~mm}$; ídem inferior, $34 \times 28 \mathrm{~mm}$. EXTREMIDADES: polifracturamiento. Húmero, parte de epífisis inferior, dando la impresión de medio desarrollo. Fémur, cabeza incompleta; diámetro, $28 \times 25$. Fuerte trocánter y láminas gruesas. ROA.

T. 184. Examen anatómico de los restos óseos: 124 fragmentos y esquirlas. CRÁNEO: fragmentos grandes que se articulan parcialmente y se deduce un cráneo de pequeña capacidad. Suturas de grandes dentellones soldadas. Una apófisis mastoides de poco tamaño. Grosores de 3 a $8 \mathrm{~mm}$. Mandíbula, los dos cóndilos: derecha, $18 \times 18 \mathrm{~mm}$; índice, 44,44. Izquierdo, $7,7 \times 17,5 \mathrm{~mm}$; índice, 44. TÓRAX: altura de cuerpo en costillas, $11 \mathrm{~mm}$. EXTREMIDADES: (H-R-F-Ca). Húmero, epífisis inferior, soldadura a término. Radio, cabeza soldada; diámetro, $16 \mathrm{~mm}$; del cuello, $9 \mathrm{~mm}$, y a nivel de tuberosidad bicipital, poco desarrollada, $12 \mathrm{~mm}$. Fémur, cabeza incompleta; diámetro, ¿42 mm? CALCÁNEO: incompleto, que no se quemó. Buen tamaño.

Resumen: individuo anatómicamente alofixo. Ajuar ambiguo, escaso. ¿Hembra?

T. 186. Examen anatómico de los restos óseos: 49 fragmentos y esquirlas. CRÁNEO: sólo esquirlas. VÉRTEBRAS: axis, o segunda vértebra cervical. Altura total, $26 \mathrm{~mm}$; de la apófosis odontoides, $12 \mathrm{~mm}$. Canal raquídeo, diámetro transversal, $21 \mathrm{~mm}$. Cuerpos de vértebras dorsales, sólo alturas, de 18 a $22 \mathrm{~mm}$. En una vértebra lumbar, diámetro carilla superior, $26 \times 39 \mathrm{~mm}$. EXTREMIDADES: intensa polifracturación, esquirlas.

Resumen: individuo anatómicamente alofixo. Ajuar ambiguo, una fusayola y poca cerámica. ¿Hembra?

T. 187. Examen anatómico de los restos óseos: 49 fragmentos y esquirlas. CRÁNEO: dentellones grandes, sinostosis en cara interna. Apófisis mastoides de poco volumen. Grosores de 5 a $8 \mathrm{~mm}$. VÉRTEBRAS: en un cuerpo vértebra dorsal, altura de $23 \mathrm{~mm}$. EXTREMIDADES: intensa polifractura, espesores en diáfisis (?) de poco valor. Fracturas lineales y en pico de flauta.

Resumen: Individuo anatómicamente alofixo, poco complexo. Ajuar de varón (falcata, lanza, escudo, fíbula, fusayola). Ejemplo de varón de tipo grácil anatómicamente, pero cuyo dato sexo es necesaria la valoración del ajuar. 
T. 190. Examen anatómico de los restos óseos: 83 fragmentos y esquirlas. CRÁNEO: dentellones medianos. Sinóstosis en cara internal Reborde orbital, frontal, fino. Grosores de 4 a $7 \mathrm{~mm}$. VÉRTEBRAS: axis o segunda vértebra cervical; altura de la apófisis odontoides, $18 \mathrm{~mm}$. EXTREMIDADES: intensa polifracturación, esquirlas lineales y en pico de flauta. Láminas gruesas. ROA.

Resumen: individuo anatómicamente alofixo, sobre más de 20 años. Ajuar de varón (lanza, cuchillo afalcatado), pero con otro lote de cerámicas y ungüentarios propios de enterramientos femeninos y que según $D$. Emeterio podrían ser «intrusos».

T. 191. Examen anatómico de los restos óseos: 115 fragmentos y esquirlas. CRÁNEO: reborde orbitofrontal grueso. Sinóstosis interna, dentellones grandes. Grosores de 5, 7, 9 y $10 \mathrm{~mm}$. Esfenoides, apófisis pterigoides de buen tamaño, sin retracción. Maxilar derecho, restos de alvéolos de $\mathrm{I}-\mathrm{I}$ y de C-P-P con restos de sus raíces y coronas, con usura de $1 .^{\circ}$; un $\mathrm{M} 1$, saltado, con usura de $2 .^{\circ}-3 .^{\circ}$ En el lado izquierdo, restos de $M 1$, "fundido" y alvéolo de $M 2$, grande. Velo de paladar, diámentro a nivel de M2, $19 \mathrm{~mm}$. Estimándose sus medidas de $33 \times 38 \mathrm{~mm}$ ? Índice, 84,2 . Orificio nasal en inaipe francés? Malar, parece de buen tamaño. Mandíbula, un P2 y M1-M2 estallados, alvéolo de M3 grande. Cóndilos de $16 \times 16 \mathrm{~mm}$. Índice, 37,5. Diámetros de cuello, $6 \mathrm{~mm}$. VÉRTEBRAS: en cuerpo de dorsal, diámetros superiores, $30 \times 27 \mathrm{~mm}$. Altura, $20 \mathrm{~mm}$. Carillas soldadas. En vértebra lumbar, $24 \times 34 \mathrm{~mm}$. Altura, $26 \mathrm{~mm}$. Índice, 70,5. EXTREMIDADES: en clavícula, diámetro, $7 \times 11 \mathrm{~mm}$. Osificada. Radio, cabeza (1), $20 \mathrm{~mm}$; en el cuello, $11-12 \mathrm{~mm}$. Altura del reborde la cabeza articular, $10 \mathrm{~mm}$. Osificada. Fémur, cabeza articular incompleta; diámetros estimados ?, 38 a $49 \mathrm{~mm}$. Soldada. ROA.

Resumen: Individuo anatómicamente varón. Ajuar: armas (falcata, escudo, fusayola).

T. 196. Examen anatómico de los restos óseos: 216 fragmentos y esquirlas. CRÁNEO: suturas dentellones medios. Grosores de 5 a 6 y $10 \mathrm{~mm}$. Malar, reborde orbital grueso. Maxilar, con parte del velo de paladar, excavado, profundo. Mandíbula, cuerpo robusto, alvéolos de C-P$P$, ocluidos por desprendimientos in vivo y retracción de los M1-M2 y abierto el M3. Cóndilo, medidas estimadas, $5 \times 17 \mathrm{~mm}$. Índice, 29,4. Sutura esfenobasilar soldada (data edad). VÉRTEBRAS: axis o segunda vértebra cervical. Altural total, $37 \mathrm{~mm}$; de la odontoides, $15 \mathrm{~mm}$. Transverso total estimado, $48 \mathrm{~mm}$ ? En vértebras dorsales, carilla superior, $29 \times$ $24 \mathrm{~mm}$; altos, $18 \mathrm{~mm}$. En vértebra lumbar, carilla con "sindesmofitos" grandes. Cara superior, cuerpo, $27 \times 37 \mathrm{~mm}$; alto, $22 \mathrm{~mm}$. EXTREMIDADES: Omóplatos, cavidad glenoidea izquierda, $32 \times 22 \mathrm{~mm}$. Índice, 
68,7. Radio, epífisis superior con fuerte tuberosidad bicipital. Carilla articular, $18 \mathrm{~mm}$; del cuello, $11 \mathrm{~mm}$. Altura borde cabeza, $9 \mathrm{~mm}$. Fémur, epífisis superior soldado, con parte del trocánter menor desarrollada y línea áspera de buen desarrollo. Tibia, meseta incompleta, al parecer de buen tamaño. Astrágalo incompleto, que concuerda con un buen desarrollo.

Resumen: individuo anatómicamente varón, mayor de 30 años. No tenía ajuar. Ejemplo de tumba sin ajuar, pero al poderse examinar sus restos óseos han permitido hacer una valoración sobre sexo y edad.

T. 200. Tumba «Principesca" de la que NO se han examinado sus restos óseos. Contenía un abundante repertorio de armas y arreos de caballo. Restos de maderas labradas y abundante ajuar femenino. Cerámicas de gran calidad y quizá partes de un telar.

Así como en la tumba 196 con una carencia de ajuar se pudo llegar al diagnóstico de edad y sexo, en este caso la carencia del estudio anatómico no ha permitido confirmar que se trate de un enterramiento doble de varón y hembra, como parece deducirse del abundante y doble ajuar.

T. 201. Examen de los restos óseos: 64 fragmentos y esquirlas. CRÁNEO: parte de órbita derecha pequeña. No se aprecia soldadura de la fontanela bregmática. Peñascos no soldados. Maxilares derecha-izquierda en sus arcadas los "gérmenes" dentarios de I-I-C-P-P derecha y de P-PM1 en la izquierda. TÓRAX: 11 costillas derecha y 10 izquierda, cabezas sin soldar. VÉRTEBRAS: 22 hemivértebras y primera vértebra sacra. EXTREMIDAD SUPERIOR: clavículas, largo, $50 \mathrm{~mm}$ ?, sin soldar. Omóplatos sin soldar. Húmeros, fragmento de tercio inferior derecho-izquierdo, sin soldar. Cúbitos, largo total, ¿68 mm?, sin soldar. Tibias, largo total, ¿76 mm? Diez fragmentos de metacarpianos y metatarsianos, sin soldar.

Resumen: Restos óseos no cremados de un lactante sobre cinco o seis meses. Ajuar: un anillo de cobre y una cuenta vítrea.

T. 203. Examen anatómico de los restos óseos: 116 fragmentos y esquirlas. CRÁNEO: suturas de dentellones medios, sinóstosis en cara interna. Grosores de 6 a $7 \mathrm{~mm}$. Reborde orbital grueso, redondeado. VÉRTEBRAS: axis, altura total, $28 \mathrm{~mm}$; de la apófisis odontoides, $20,5 \mathrm{~mm}$. En otro cuerpo, diámetros, $13 / 14 \times 20 / 21 \mathrm{~mm}$. Alturas 11-12 mm. EXTREMIDADES: omóplato, cavidad glenoidea, $29 \times 22 \mathrm{~mm}$. Índice, 75,8. Fémur, epífisis superior, cabeza incompleta $(1,2)$; diámetro, 35 ?; altura, $30 \mathrm{~mm}$; del cuello, $20 \times 24 \mathrm{~mm}$. Trocánteres de poco desarrollo y línea áspera y otras inseciones musculares acentuadas. Rótula, altura estimada $36 \mathrm{~mm}$. Pelvis, escotadura ciática de ángulo abierto, redondeado (característica femenina). 


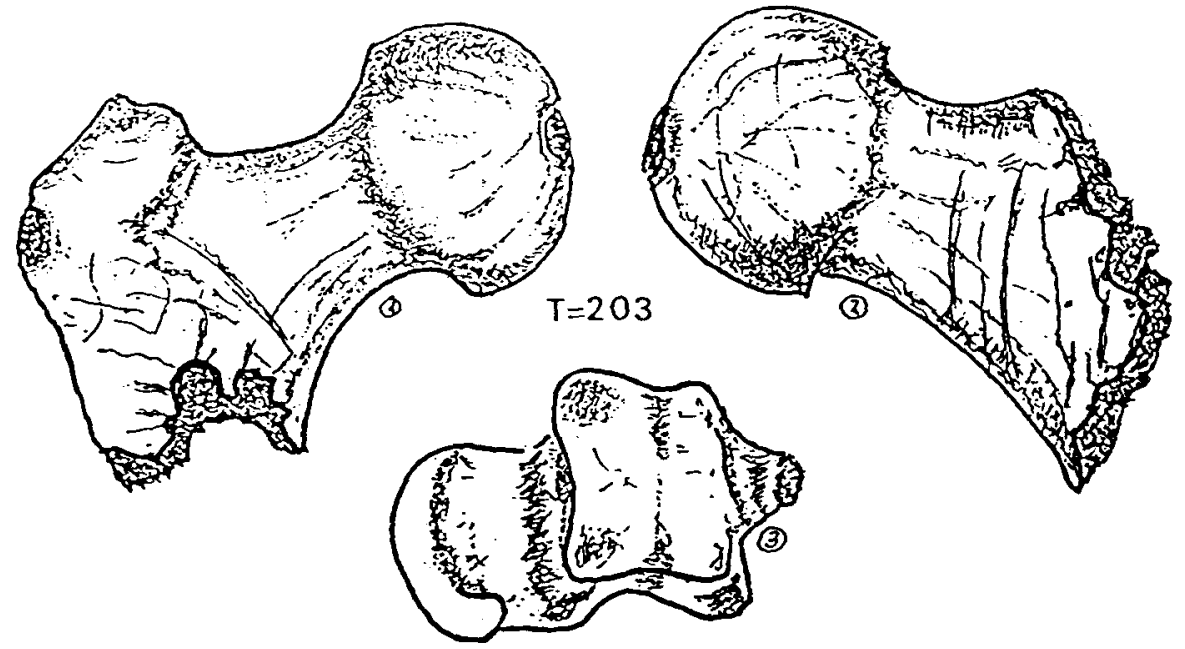

Fig. 13.

Resumen: individuo anatómicamente alofixo, ¿hembra?. Ajuar: dos fusayolas. Edad más o menos 20 años.

T. 204. Se han estudiado un conjunto de tres "paquetes" de restos óseos contenidos en tres vasijas: uno, en una urna con 131 fragmentos y esquirlas; otro, dentro de un ánfora con 88 , y un tercero con 159, sin vasija o contenedor, en total 378 fragmentos y esquiquilas, muchos más de los segundos que de los primeros. Se trata, pues, de una tumba compleja, en al que estudio osteológico ha puesto de manifiesto la cremación de dos individuos, uno hembra, otro varón, con sus ajuares correspondientes, que pudo ser simultánea, ya que en alguno de los "paquetes" se han identificado fragmentos óseos de ambos, en concreto vértebras de uno con restos del otro.

Examen anatómico de los restos óseos:

CRÁNEO: partes de suturas de pequeños dentellones, con sinóstosis iniciada en su cara interna. Uno de los peñascos de tamaño pequeño y la protuberancia occipintal interior de poco volumen, así como el arranque de la apófisis zigomática y cavidad condiloidea; dos molares estallados, raídes cementadas y usura inicada. Grosores de 4 a $6 \mathrm{~mm}$. VÉRTEBRAS: partes de cuerpos con las carillas terminando sus soldaduras. En vértebra cervical, alturas de 13 a $14 \mathrm{~mm}$. En vértebras dorsales, diámetros: carilla superior, $24 \times 22 \mathrm{~mm}$; idem inferior, $29 \times 22 \mathrm{~mm}$. Altos, 13, 14, 16 y $18 \mathrm{~mm}$. Canal raquídeo transverso, $18 \mathrm{~mm}$. Sacro, primera vértebra sin 
soldar a la segunda (data edad menor de 25 años). EXTREMIDADES: intensa polifracturación crematoria. Húmero, partes de la epífisis superior e inferior, terminando su soldadura y láminas de diáfisis de grosores medios, dando impresión de individuo poco corpulento. Pelvis, escotadura ciática abierta; las dos carillas sinfisiarias del pubis (pequeñas porciones óseas que al encontrarse duplicadas han permitido confirmar la doble cremación y la diferencia de edad entre ellos) que según los estudios de Brooks y Ahmed y su esquema se pueden incluir en el grado $1 .^{\circ}$ que data una edad de 17 a 19 años.

\section{Examen anatómico del tercer «paquete» óseo:}

CRÁNEO: suturas de grandes dentellones, con sinóstosis de su cara interna. Mandíbula, rama ascendente y ángulo mandibular robustos, con crestas acentuadas del masetero. EXTREMIDADES: la intensa polifracturación dificulta la identificación de los huesos a que pertenecen fragmentos y esquirlas, dando la impresión general de tratarse de un individuo adulto y de fuerte complexión. Radio, epífisis superior, soldada, con tuberosidad bicipital muy desarrollada (inserción del bíceps); diámetro en cuello, $16 \mathrm{~mm}$. Pelvis, al igual que en otro lote se identifican las dos carillas pubianas, a clasificar, según el esquema de Brooks-Ahmed, en el grado 8-9? y una edad sobre 38-45 años.

Resumen: restos de la cremación de dos individuos, depositados en una sola tumba, por tanto, doble, identificados por el estudio anatómico $y$ de sus ajuares como de una hembra, joven, menor de 25 años, y de un varón mayor de 35 años (ajuares: falcata, puñal, escudo, soliferrum, lanza, fíbulas, tabas, fusayolas, cuentas collar, anillos, adornos pasta vítrea, apliques de pasta vítrea, esfinge o grifo, y otras).

T. 207 y 208. Ambas están revueltas, sin delimitar, si bien los restos de ajuar son escasos y, al parecer, unos de varón (una falcata) y otros de hembra (anillo, tres fusayolas, cerámica ibérica fina), pero no parece una tumba doble. Se han examinado anatómicamente restos de un solo individuo: 57 fragmentos y esquirlas. CRÁNEO: parte de la sutura sagital, de grandes dentellones, sin soldar. Grosores entre 7 y $10 \mathrm{~mm}$. VÉRTEBRAS: fragmentos de cuerpos y apófisis, terminando las carillas de osificar ?? Alturas sobre $20 \mathrm{~mm}$. EXTREMIDADES: polifracturación intensa, dando los fragmentos de diáfisis la impresión de individuo corpulento.

Resumen: individuo anatómicamente varón sobre menos de 20 años.

T. 209. Tumba invadida en su construcción por la 127, pero con los dos nichos bien individualizados. El examen anatómico de los restos de ambas tumbas coinciden en que se trata de dos posibles varones de tipo grácil. El estudio de este otro es: CRÁNEO: fragmento de maxilar, con 
parte del velo del paladar sin soldar y sus medidas calculadas son $24 \mathrm{x}$ $24 \mathrm{~mm}$. Índice sobre 100. Mandíbula, parte de la rama ascendente de aspecto grácil. VÉRTEBRAS: fragmentos de cuerpos, no individualizable, dando la impresión de individuo grácil. Alturas de vértebras ? sobre 17, 18 y $21 \mathrm{~mm}$. Carillas soldadas. Parte del sacro, con la primera sin soldar a segunda (data edad); diámetro superior, $31 \times 42 \mathrm{~mm}$. EXTREMIDADES: pequeño fragmento de cabeza de húmero, soldadura a término. Pelvis, fragmento con parte de la cavidad cotiloidea, soldada.

Resumen: individuo anatómicamente de tipo grácil, edad sobre menos de 20 años, alofixo, varón por el ajuar de armas, con la interrogante de los adornos. En este caso llama poderosamente la atención la pobreza de los restos óseos y un ajuar abundante y variado propio de un varon adulto y fuerte, ya que a las armas se une un variado repertorio de aperos agrícolas, pero además también existen adornos variados y ricos, con lo que se plantea la duda de si sólo se recogieron post-cremación los restos de una mujer y no los del varon. En fin, las dudas que lleva consigo el análisis osteológico, exclusivamente anatómico, que sólo se podrán resolver cuando contemos con otros medios analíticos (cromosónicos, químicos...). Ajuares: falcata, escudo, lanza, soliferrum, hoz, podaderas, hacha, abrazaderas, anillas, punzones, etc. Anillos, fíbulas (6), torques, navaja de afeitar, discos vítreos, cerco lámina de oro, pendientes oro, 150 tabas, piedra afilar, etc.

T. 210. Examen anatómico de los restos óseos: 139 fragmentos y esquirlas. CRÁNEO: láminas saltadas, estalladas ? Grosores de 3-4 mm. Fragmento de temporal con el arranque de la mastoides y del arco zigomático de un aparente desarrollo medio. Mandíbula, parte del arco dental con restos de los alvéolos de I-I-C-P-P-M1 y M2, de dientes definitivos, de poco tamaño. EXTREMIDADES: intensa polifragmentación, estrías lineales y en pico de flauta. El aspecto general es de poca robusted. ROA.

T. 211. En el libro de E. Cuadrado ya se apunta que esta tumba y la anterior son probablemente de una sola cremación. Se han estudiado dos "paquetes" con la signatura T-210 y T-211, que contrastados anatómicamente concuerdan como del mismo individuo y cuyo pormenor es el siguiente: CRÁNEO: suturas de finos dentellones, sin soldar. Grosores como en la anterior. VÉRTEBRAS: no existían en la anterior; hay fragmentos de cuerpos sin posibles medidas, pero concordantes con el aspecto general de poca robustez. Sacro, fragmento de primera vértebra que parece estar sin soldar a segunda. EXTREMIDADES: en general son esquirlas que confirman la impresión de individuo poco robusto.

Resumen: individuo de naturaleza grácil, en edad juvenil, sobre 17-20 años. Alofixo-hembra. Ajuar femenino (en la 210: dos fusayolas, taba y un 
anillo. En la 211: pendiente de planta, cuentas de collar pasta vítrea y colgante, dos anillos de bronce). Por tanto, T-210 y T-211 se deben refundir en una sola.

T. 212. Examen anatómico de los restos óseos: 100 fragmentos y esquirlas. CRÁNEO: en su mayoría esquirlas. Porción de sutura parietotemporal iniciada la sinóstosis en cara interna. Grosores, $4 \mathrm{~mm}$. EXTREMIDADES: intensa polifractura, estrías lineales y en pico de flauta. Impresión de poca corpulencia.

Resumen: Nuevamente llamamos la atención en el contraste entre una tumba importante por su construcción, un monumento de tres escalones con torrecilla, y sus escasos restos óseos, de un individuo anatómicamente grácil, alofixo, con un ajuar de varón (falcata, escudo, lanza, fíbula anular, restos metálicos).

T. 213. Examen anatómico de los restos óseos: 15 fragmentos. CRÁNEO: parte de sutura sagital de dentellones pequeños, sin soldar. Grosores, $3 \mathrm{~mm}$. Un molar inferior, estallado; corona de $5 \times 9 \mathrm{~mm}$, raíces soldadas de $9 \mathrm{~mm}$. EXTREMIDADES: partes de cabeza de húmero, soldadura en vías de consolidar; diámetros, ¿30 mm? Fémur, como en el hueso anterior, terminando de soldar su epífisis. Astrágalo parece de pequeño tamaño.

Resumen: individuo juvenil sobre más de 16 años, alofixo-hembra por el ajuar (plaquita de hueso labrado, broche de oro, cardium y colgante, cuentas collar vitreas, dos anillos y fibula, nueve fusayolas).

T. 214. Examen anatómico de los restos óseos: 32 fragmentos y esquirlas. CRÁNEO: láminas sin soldar, estalladas. Suturas de pequeños dentellones. Grosores de 2 a $3 \mathrm{~mm}$. EXTREMIDADES: Polifracturación que no permiten medidas y dan la impresión de individuo muy joven.

Resumen: Los pocos datos anatómicos obtenidos, sólo permiten la impresión general de individuo muy joven, niño/a, cremado. Ajuar cerámico. Edad 7 a 10 años.

T. 216. Examen de los restos óseos: 117 fragmentos y esquirlas. CRÁNEO: porción de sutura sagital, dentellones grandes, soldada. Grosores, 3 a $6 \mathrm{~mm}$. Temporal, porción mastoidea derecho-izquierdo de desarrollo medio y un peñasco voluminoso. EXTREMIDADES: húmero, parte de epífisis superior, soldadura, igual en cabeza de fémur; diámetro, ¿37 $\mathrm{mm}$ ? Astrágalo izquierdo; largo, ¿50 mm?; ancho en la tróclea, ¿27 mm?

Resumen: individuo anatómicamente hembra, de más de 30 años. Ajuar: adornos (tres anillos, cuatro agujones del pelo, fusayolas, conchas, fibula o brazalete). 
T. 217. Examen anatómico de los restos óseos: 132 fragmentos y esquirlas. CRÁNEO: láminas sin soldar, saltadas. Suturas de pequeños dentellones, sin soldar. Grosores, 4 a $6 \mathrm{~mm}$. Temporal, parte de mastoides derecho-izquierdo, de poco volumen. Peñascos derecho-izquierdo concordantes. Mandíbula, ángulo abierto. Altura de sínfisis, $23 \mathrm{~mm}$. Arco dentral, alvéolos de I-I-C pequeños. VÉRTEBRAS: partes de cuerpos vértebras dorsales; alturas, ¿25 mm? Sacro, fragmento dando la impresión de pequeño tamaño. EXTREMIDADES: intensa polifracturación, lineales y en pico de flauta. Fémur: fragmento de cabeza; diámetro, $40 \mathrm{~mm}$; alto, ¿32 $\mathrm{mm}$ ? En otros línea áspera poco desarrollo. Astrágalo de tamaño medio. Largo, ¿20-25 mm? ROA.

Resumen: Individuo anatómicamente grácil, juvenil, alofixo. Ajuar de varón (falcata, escudo, lanza, solifereum, espuela, dos fíbulas, anillo, aguja de hueso...).

T. 220. Examen anatómico de los restos óseos: 68 fragmentos y esquirlas. CRÁNEO: fragmentos de suturas de dentellones medianos, sin soldar. Grosores, 3 a $7 \mathrm{~mm}$. Malar, fragmento de apófisis orbital, grosor medio. Maxilares derecho-izquierdo, parte del velo de paladar, excavado, profundo; ancho, i34 mm? Alvéolos derechos de I-I-C-P-P- M1 y M2 e izquierdos de $1-1-C-P$, dientes permanentes. Mandíbula, cóndilo izquierdo de $12 \times 9 \mathrm{~mm}$. Índice, 75. Diámetro en cuello, $5 \mathrm{~mm}$. TÓRAX: fragmentos de costillas; diámetros en cuello costal, $9 \mathrm{~mm}$. EXTREMIDADES: intensa polifracturación, lineales y en pico de flauta, dando la impresión de poca robustez.

Resumen: individuo grácil, adulto, mayor de 20 años. Anatómicamente alofixo. Ajuar de varón (falcata, escudo, lanza, anillos).

T. 221. Examen anatómico de los restos óseos: 36 fragmentos y esquirlas. CRÁNEO: esquirlas. Grosores de 4 a $6 \mathrm{~mm}$. VÉRTEBRAS: fragmentos vértebras dorsales; alturas cuerpo, i23 mm? EXTREMIDADES: intensa polifracturación en un fragmento de cabeza de húmero parece estar en vías de soldadura. ROA.

Resumen: individuo anatómicamente en edad juvenil, alofixo. Ajuar de hembra (braserillo?, tres fusayolas, anillo plata, varillas de hierro).

T. 222. Examen anatómico de los restos óseos: 45 fragmentos y esquirlas. CRÁNEO: suturas con dentellones de tamaño medio. Grosores de 4 a $6 \mathrm{~mm}$. EXTREMIDADES: intensa polifracturación, lineales y en pico de flauta, impresión de poca robusted. ROA.

Resumen: individuo anatómicamente alofixo, edad juvenil. Ajuar femenino (fusayolas). 
T. 223. Examen anatómico de los restos óseos: 45 fragmentos y esquirlas. CRÁNEO: frontal, reborde orbital fino. Senos frontales grandes. Glabela poco desarrollo (2. ${ }^{\circ}$ Broca). Temporal, arranque apófisis zigomática y cavidad glenoidea medias. Suturas sin soldar. Occipital, sutura esfenobasilar sin soldar (data edad de menos de 20 años). Estos fragmentos permiten trazar un perfil ideal de este cráneo, dando una impresión de volumen pequeño. Dientes, M1-corona, $11,3 \times 8,8 \mathrm{~mm}$. Usura $3 .^{\circ}-4 .^{\circ}$, carbonizado, raíces grandes, partes de un incisivo y un premolar.

T. 472 y 473 . Estudio osteológico de los restos óseos: gran número de esquirlas y fragmentos por la intensa fracturación crematoria; muy carbonizados. CRÁNEO: láminas con diploe, estalladas. Suturas de grandes dentellones, sinóstosis iniciada en cara interna. Grosores de 6 a $8 \mathrm{~mm}$ y $11 \mathrm{~mm}$ en protuberancia occipital interna. EXTREMIDADES: el gran número de esquirlas dificulta las medidas e identificación ósea. La impresión general es la de huesos robustos, un metacarpiano de $75 \mathrm{~mm}$ y una falange, fragmento de rótula, da impresión de buen tamaño, robusta y un fragmento de la cresta tibial acusada, robusta, ¿platicnemia?, diámetro transverso sobre $25 \mathrm{~mm}$ ?, espesor de 6-7 mm. ROA y escorias metálicas.

Resumen: No hay fragmentos específicos, por el aspecto general de robustez, se puede tratar de un adulto, varón.

T. 498. Gran número de esquirlas y fragmentos, cremados, que permiten pocos datos. En general presentan poco diámetro y espesor de paredes. CRÁNEO: "Cascarillas", fragmentos de occipital de 4 a $6 \mathrm{~mm}$ de grosor y crestas poco acusadas. EXTREMIDADES: húmero, epífisis superior, fragmento de cabeza articular sin soldar. Una falange de $18 \mathrm{~mm}$. Pelvis, fragmento del acetabulun, parece de poco diámetro y profundidad. Diáfisis, espesores de 2 a $4 \mathrm{~mm}$, en uno de fémur; diámetro anteriorposterior, $23 \mathrm{~mm}$.

Resumen: Niño/a mayor de un año.

T. 500. Escaso número de fragmentos y esquirlas, cremados. CRÁ NEO: "cascarillas", grosores de 2 a $3 \mathrm{~mm}$. Suturas de pequeños dentallones, abiertas. Frontal, fragmento del reborde orbital, al parecer de órbita pequeña. Temporal, fragmento de peñasco izquierdo incompleto, sin soldar, tamaño pequeño. EXTREMIDADES: huesos largos de poco grosor, 2$3 \mathrm{~mm}$. Fémur, epífisis superior, sin soldar. Tibia, fragmento de la meseta, sin soldar. Diámetros en diáfisis femoral, $26 \times 13 \mathrm{~mm}$ y en tibial, $25 \times$ ?? $\mathrm{mm}$.

Resumen: Niño/a mayor de un año. 
T. 504. Se reciben los restos óseos en dos «paquetes» (1) y (2), que una vez clasificados se comprueba que están mezclados en ambos, los restos de dos cremados, uno infantil y otro un adulto.

Restos óseos infantiles: CRÁNEO: escasos y pequeños fragmentos. Frontal, parte de reborde orbital fino que proyecta una órbita pequeña. Grosores de 4 a $7 \mathrm{~mm}$. Mandíbula, fragmentos de apófisis coronoides derechos, pequeño, que puso en aviso sobre la posibilidad de restos óseos de un infantil. EXTREMIDADES: pequeños fragmentos y esquirlas que por su aspecto general débil, gráciles y espesores de $3 \mathrm{~mm}$ son propios de un niño/a cremado.

Restos óseos de adulto: CRÁNEO: frontal, fragmento con parte de la espina, gruesa y senos desarrollados; grosores, $13 \mathrm{~mm}$ en glabela y $6 \mathrm{~mm}$ en escama; otro orbital, borde redondeado. Parietal de 5-6 mm de grosor, partes de suturas sinostosadas. Occipital, $14 \mathrm{~mm}$ en protuberancia. EXTREMIDADES: abundantes esquirlas por la intensa fracturación crematoria, no hay nada de las epífisis. Grosor de paredes diáfisis de 3, 5 y $7 \mathrm{~mm}$. Un diámetro femoral en tercio superior, $25 \mathrm{~mm}$. Tibia, acusada cresta tibial, ¿platicnemia?

Resumen: la mezcla de restos óseos plantea la posibilidad de ser una tumba doble de una niña/o de un año y un adulto alofixo, probable hembra.

T. 505 y 506 . Restos óseos en dos bolsas $\sin n .^{\circ}$ correspondiente, que una vez clasificados permiten identificarlos como de un solo individuo (misma coloración, grosores, líneas de fractura...). CRÁNEO: frontal, parietal y temporal, grosores de 3 a $7 \mathrm{~mm}$. Suturas de pequeños dentellones, iniciando sinóstosis interna. Láminas saltadas, estalladas. Frontal, reborde orbital fino. Temporal, fragmento zona mastoidea de desarrollo medio. Maxilar, rstos de los alvéolos C-P.P. EXTREMIDADES: húmero, epífisis incompleta, cabeza, soldadura terminal, diáfisis de $19 \times 16 \mathrm{~mm}$; paredes, $3 \mathrm{~mm}$. Pelvis, fragmentos del acetabulum, diámetro sobre $37-40 \mathrm{~mm}$, soldadura terminal. Fémur, epífisis superior, bola articular sobre $36-40 \mathrm{~mm}$, diáfisis sobre $24 \mathrm{~mm}$; paredes, $6 \mathrm{~mm}$; en otro, línea áspera poco marcada. Astrágalo, porción de la tróclea; ancho, $38 \mathrm{~mm}$.

Resumen: individuo adolescente, probablemente hembra.

T. 517. Gran número de pequeños fragmentos y esquirlas, con sus consiguientes dificultades métricas e identificatorias. CRÁNEO: frontal, reborde orbital redondeado, glabela roma; grosor, 3-4 mm. Parietales, peñasco derecho incompleto, soldado; grosores, 5-6 mm. Porciones de suturas de medianos y pequeños dentellados, sinóstosis interna. Temporal, porción de mastoides, parece grande, surco digástrico profundo y arran- 
que de la zigomática de buen desarrollo. Occipital, fragmento de la apósifis basilar, soldándose un hueso wormiano; grosor en protuberancia interna-externa, $10 \mathrm{~mm}$. Malares incompletos, borde orbital redondeado. Maxilar, alvéolos izquierdos de I-I-C-P-P de dientes definitivos. Mandíbula, alvéolos I-I izquierdos; I-I-C-P-P-M1, apófisis geni de poco relieve; alto de sínfisis, $25 \mathrm{~mm}$., se aprecia alvéolo de M3 abirto, rama ascendente poco robusta, con estrías de cremación profundas. Su ancho sobre $30-32 \mathrm{~mm}$ y espesor de $7 \mathrm{~mm}$. No conserva cóndilo; diámetro máximo de la escotadura, $22 \mathrm{~mm}$; ángulo goniaco, 84 grados. Dientes, un premolar y un molar superior, con la corona estallada, ¿usura de 2. ? TÓRAX: Costillas, altura en cuerpo sobre 11-13 mm. VÉRTEBRAS: cuerpos incompletos. En uno, cervical; diámetro, $16 \times 22 \mathrm{~mm}$; en uno, dorsal, altura, $26 \mathrm{~mm}$, y en uno lumbar, diámetro superior, $23 \times 24 \mathrm{~mm}$; alto, $23 \mathrm{~mm}$. EXTREMIDADES: húmero, epífisis superior soldadura terminal? Epifisis inferior con inicio transverso máximo de $50 \mathrm{~mm}$. Diámetro en tercio medio de 16$18 \mathrm{~mm}$ y espesores, $4 \mathrm{~mm}$. Radio, diámetro a nivel de tuberosidad bicipital, $14 \mathrm{~mm}$. Cúbito, diámetro, $10 \times 9 \mathrm{~mm}$. Metacarpiano de $50 \mathrm{~mm}$ de largo. Dos huesos del carpo. Pelvis, fragmento de la escotadura ciática, abierta. Fémur, hueso denso, 6-7 mm; línea áspera desarrollada, diámetros sobre $32 \times 21 \mathrm{~mm}$. Rótula, parece densa, robusta; grosor, $18 \mathrm{~mm}$ derecha, y $16 \mathrm{~mm}$ izquierda. Tibia, espesor, $7 \mathrm{~mm}$; cresta de angulo abierto. Astrágalo, fragmento de la tróclea; ancho, $32 \mathrm{~mm}$. ROA y fragmentos de hierro.

Resumen: individuo adulto, varón, mayor de 20 años.

T. 518. Intensa fracturación crematoria, al clasificarlos se aprecia que están mezclados restos de dos individuos, unos infantiles y otros de un adulto.

Restos óseos infantiles: CRÁNEO: grosores de 2 a $4 \mathrm{~mm}$. Suturas de pequeños dentellones. Temporal, peñasco izquierdo más bien pequeño; largo calculado, $33 \mathrm{~mm}$, sin soldar. Maxilar izquierdo, con parte del velo de paladar y restos alveolares de I-I-C-P. Dientes, raiz de incisivo, ¿decidual? VÉRTEBRAS: parte de una cervical, impresión de poco tamaño. EXTREMIDADES: esquirlas de huesos largos de poco calibre y espesor, diámetro sobre 8 y $12 \mathrm{~mm}$.

Restos óseos de adulto: CRÁNEO: láminas con diploe, estalladas, saltadas. Grosores, 5-7 mm. Frontal, borde orbital redondeado, fino. Temporal, fragmento con la cavidad glenoidea de tamaño medio. Maxilar, porción de la rama ascendente izquierda y arco alveolar con restos de los alvéolos de I-I-C-P-P-M1 y M2 a cuyo nivel está fracturada y no se aprecia si está abierto el M3. EXTREMIDADES: húmero, epífisis superior incompleta, restos de cabeza articular, pared de medio tamaño, y en soldadura 
terminal, diámetro en diáfisis sobre $17 \mathrm{~mm}$; espesor, 5-6 $\mathrm{mm}$. Carpo, dos huesos. Fémur, espesor sobre $6 \mathrm{~mm}$. Peroné, fragmento de la epífisis superior soldada. Calcáneo, incompleto, deformado, tamaño medio soldadura a término.

Resumen: dada la mezcla que presentan estos restos se puede pensar en una tumba doble de niño/a y un adulto joven, ¿hembra?, edades posibles, al no contar con fragmentos específicos, sobre más de un año del niño/a y sobre 18 años del adolescente.

T. 519. Entre los restos se aíslan carbones vegetales y algunos fragmentos de hierro. CRÁNEO: Grosores de 3 ó $5 \mathrm{~mm}$. Láminas saltadas. Frontal, borde orbital redondeado. EXTREMIDADES: abundantes esquirlas de huesos largos y poco fragmentos. Fémur, un fragmento de diáfisis con acusada línea áspera, fuerte pilar, espesor de pared de 5 a $6 \mathrm{~mm}$; diámetro en el tercio medio de la diáfisis, $26 \mathrm{~mm}$. Tibia, fragmento de diáfisis con acusada cresta tibial, iplaticnemia?.

Resumen: individuo adulto, posible varón, mayor de 20 años.

T. 520. En su casi totalidad, esquirlas por la intensa fractura crematoria. Se aísla algún trocito de hierro. CRÁNEO: frontal, reborde orbital fino. Temporal, arranque de la zigomática, parece de poco desarrollo. Grosores de 3 a $5 \mathrm{~mm}$. Dientes, una raiz de ?-? o ?corona que aparece decidual y un incisivo definitivo.

Resumen: del conjunto se desprende la impresión de tratarse de un cremado en edad juvenil, alofixo, ¿varón?

T. 521. Gran cantidad de esquirlas que dificultan identificación y medidas. CRÁNEO: numerosas esquirlas, láminas saltadas, estalladas. Fragmentos con partes de suturas de medianos y grandes dentellones, iniciada la sinóstosis en cara interna. Grosores de 3 a $7 \mathrm{~mm}$. Frontal, parietal, temporal y occipital, fragmento de peñasco; tamaño grande, $35 \mathrm{~mm}$ ? Mandíbula, cóndilo izquierdo de $9 \times 19 \mathrm{~mm}$; índice, 47 , y un fragmento de temporal con la cavidad glenoidea, que concuerda. TóRAX: costillas, en un cuerpo $10 \mathrm{~mm}$ de alto. VÉRTEBRAS: cuatro apófisis de cervicales. Un cuerpo, vértebra costal, $24 \times 29 \mathrm{~mm}$; en otro, $25 \times 26 \mathrm{~mm}$. Parte de cuerpo de vértebra dorsal; alto, $25 \mathrm{~mm}$. EXTREMIDADES, gran número de esquirlas, largas, estrechas, sin clara identificación, hueso denso, robusto, blanquecino. Húmero, epífisis superior soldada; diámetros de la cabeza articular, $42 \mathrm{~mm}$; altura, $13 \mathrm{~mm}$; en diáfisis, diámetro en tercio superior, $25 \mathrm{~mm}$; en el medio, $18 \mathrm{~mm}$; paredes, $4 \mathrm{~mm}$. Mano, un metacarpiano, $45 \mathrm{~mm}$ largo. Radio, diáfisis, diámetro en tercio medio de 11 a $13 \mathrm{~mm}$. Fémur, línea áspera acentuado resalte pilástrico, paredes de 5 a 
$9 \mathrm{~mm}$; diámetro en tercio medio, $26 \times 27 \mathrm{~mm}$. Tibia, cresta redondeada; pared, $4 \mathrm{~mm}$; diámetro transversal sobre $18 \mathrm{~mm}$.

Resumen: individuo anatómicamente varón, adulto, mayor de 25 años.

T. 523. Unas 300 esquirlas que no permiten datos, coloración carbonosa. CRÁNEO: frontal, pequeños fragmentes de paredes gruesas, $6 \mathrm{~mm}$, hueso compacto. EXTREMIDADES: fragmento con el inicio de línea áspera, desarrollada, fuerte pilastra.

Resumen: por el aspecto general de las estructuras óseas, anatómicamente varón.

T. 527. Más de 200 esquirlas, coloración antes de lavado, unas carbonosas y otras blancuzcas, que parecian indicar dos cremaciones distintas, pero una vez limpios todos de color blanquecino. Abundantes restos de carbón vegetal y un fragmento de hierro, pequeño, amorfo. CRÁNEO: muy fragmentado, sin porciones suturales. Láminas separadas, estalladas. Grosores en frontal y parietal de 4 a $7 \mathrm{~mm}$ y de $13 \mathrm{~mm}$ en protuberancia occipital. Impresión general de cráneo de gran volumen. Mandíbula, apófisis coronoides derecha no grande y cóndilo de $8 \times$ $20 \mathrm{~mm}$. Índice, 40. VÉRTEBRAS: cuerpos incompletos, aspecto de bueno tamaño. EXTREMIDADES, intensa fragmentación, no hay restos de epífisis completos. Húmero, epífisis inferior parte de la polea tróclear grande (¿35$40 \mathrm{~mm}$ ?); diáfisis, $18-20 \times 16 \mathrm{~mm}$; espesor, $4 \mathrm{~mm}$. Fémur, fragmento de bola articular, soldada, línea áspera de mediano desarrollo, espesores sobre 5 a $6 \mathrm{~mm}$; diámetro en tercio medio, $24 \times 2 \mathrm{~mm}$. Tibia, fragmento de cresta redondeada.

Resumen: individuo alofixo, ¿hembra?, ¿varón joven?

T. 528. En el "paquete" aparecen entremezclados huesos de: Restos óseos de animales, restos óseos infantiles y restos óseos de adulto.

Restos infantiles: CRÁNEO: en su mayoría son fragmentos de láminas, incluso en los completos se podrían separar fácilmente las dos láminas. No hay partes suturales. Fragmento de malar iaquierdo con reborde orbital fino y proyecta una órbita media, hueso de poca consistencia. Temporal, los dos peñascos incompletos sobre $35 \mathrm{~mm}$ de largo (?), soldadura iterminal o iniciada? Otro fragmento con la apófisis mastoides pequeña, surco digástrico poco profundo. Grosores, 3 a $5 \mathrm{~mm}$. Maxilar, borde alveolar de I-I-C-P poco profundo, ¿dientes deciduales? Mandíbula, fragmento de ramas ascendente derecha, de poca consistencia que conserva el cóndilo de $8 \times 13 \mathrm{~mm}$ (?) y anchura de rama sobre $26 \mathrm{~mm}$. EXTREMIDADES: en general esquirlas, como especie de láminas de huesos poco consistentes; grosor de paredes de 2 a $3 \mathrm{~mm}$ y $5 \mathrm{~mm}$ en cresta tibial. Fragmento de metacarpiano poco tamaño, paredes finas. 

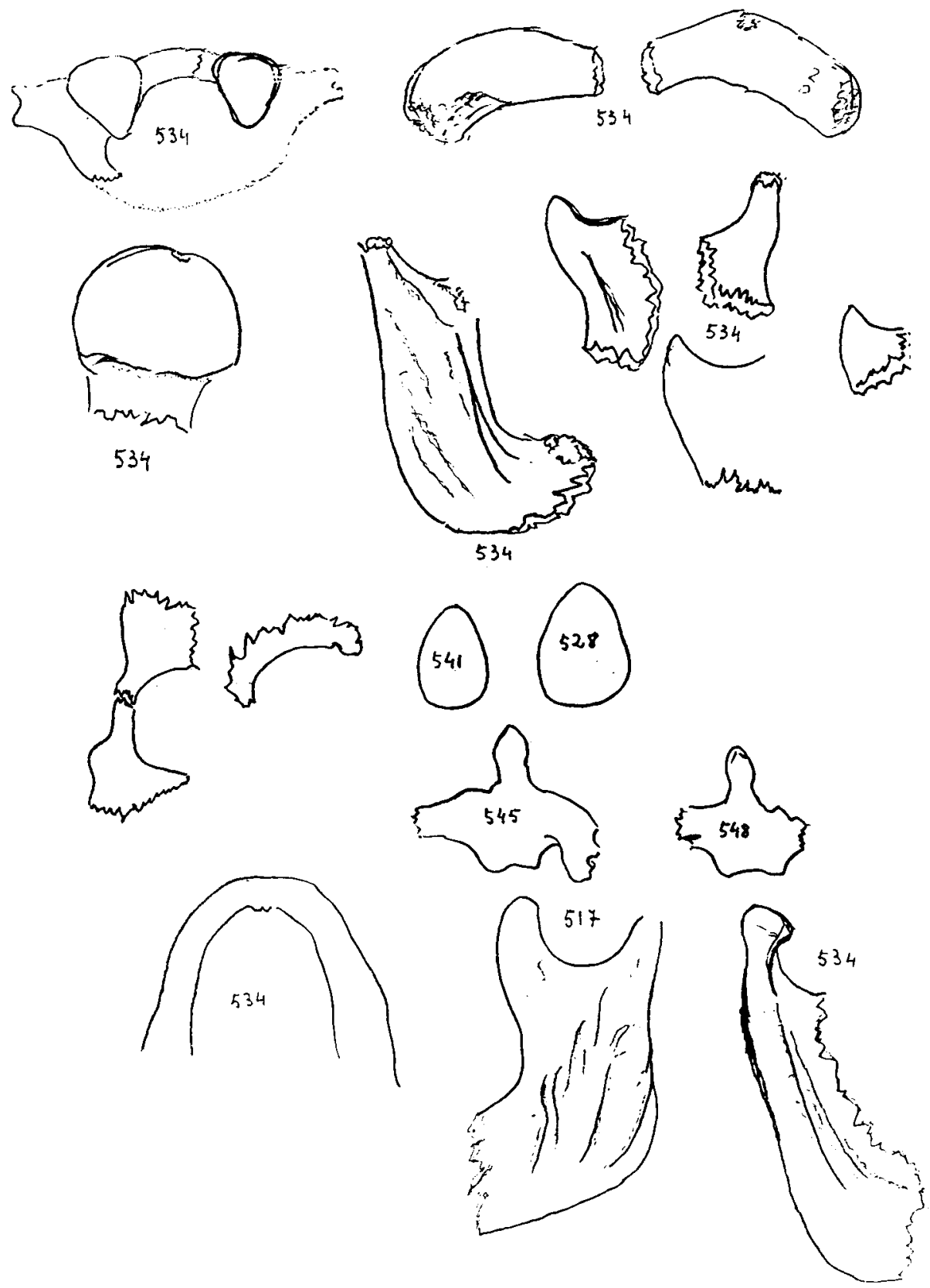

Fig. 14. 
Restos del adulto: CRÁNEO: sólo dos fragmentos, uno de parietal, grosor de 4 a $5 \mathrm{~mm}$ y otro occipital de $9 \mathrm{~mm}$. EXTREMIDADES: pequeño número de fragmentos y esquirlas de huesos muy fracturados, consistentes y robustos. Omóplato, fragmento del izquierdo con parte del acrómion y la cavidad glenoidea de $29 \times 22 \mathrm{~mm}$; índice, 75; algún fragmento del derecho. Húmero, fragmento de la epífisis superior, soldada. Fémur, fragmentos de diáfisis; espesor de pared, 6-7 mm; diámetros sobre $29 \mathrm{x}$ $27 \mathrm{~mm}$, línea áspera, fuerte columna pilástrica. Epífisis inferior, parte de uno de los cóndilos, grande, dentro, soldado. ROA.

Resumen: probable tumba doble de niño/a, mayor de un año y de un adulto alofixo, ¿varón?, ¿hembra viril?

T. 534. Se reciben, para su análisis anatómico, tres «paquetes " con el mismo número de tumba: uno con escasos fragmentos y esquirlas; otro con más de 100 esquirlas (lo que dificulta la obtención de datos métricos e identificativos) y un tercero con fragmentos más bien grandes y escasas esquirlas. Todo ello hace pensar que sufrieron una primera selección durante la excavación.

Dada la abundancia y complejidad del material óseo, se procedió a una agrupación por regiones anatómicas, del que se hace un primer resumen, que se reordenan y concluyen en el habitual final, a causa de su excepcional interés.

Restos óseos craneales:

1. Fragmentos grandes de frontal, parietales y occipital que concuerdan y que se articulan formando la bóvedad craneal, con grosores de 6 a $8 \mathrm{~mm}$ y un gran fragmento de temporal derecho con la apófisis mastoides y el peñasco de gran tamaño, soldado. Fragmento peñasco izquierdo de gran tamaño.

2. ${ }^{\circ}$ Fragmentos de los rebordes orbitarios del frontal que concuerdan y se articulan con las apófisis ascendentes de los malares, proyectando unas órbitas más bien pequeñas. Grosor, $4 \mathrm{~mm}$. Parietales, fragmento de una lámina, saltada o estallada, con una porción de sutura sagital de fino dibujo y pequeños dentellones. Occipital, fragmento interno protuberancia interior de poco desarrollo. Temporales, fragmento del izquierdo, con apófisis mastoides, de poco tamaño. Maxilar, fragmento derecho, rafe soldado, restos alveolares de C-P-P-M1 y M2, con las coronas estalladas, raíces cementadas $y$, aunque el alvéolo de $M 3$ está semidestruido, parece haber emergido. Mandíbula, una arcada alveolar, de tamaño medio, apófisis geni de poco desarrollo. Rota al inicio de las ramas ascendentes y con alraciones probables patológicas. En el lado izquierdo, alvéolos para I-I-C-P1-P2 (raíces), M1 y M2; en el lado derecho, alvéolos de I-I2-C-P1 
(raices) y no presenta los alvéolos de P2-M1 y $\mathrm{M} 2$, sino una especie de tejido trabecular que rellena la zona, con un discreto hundimiento circular en el espacio de M3 y ligera reabsorción de la lámina externa. Se aislan otra serie de fragmentos mandibulares, algunos triplicados, que plantean interrogantes sobre el número de individuos de esta tumba y se relacionan a continuación: fragmento de rama ascendente mandibular, en varios fragmentos, hueso frágil de poco espesor; anchura sobre $27 \mathrm{~mm}$ ?; ángulo goniaco, 90-92 grados (?). Cóndilo, $8 \times 17 \mathrm{~mm}$; índice, 47, lado izquierdo. Fragmento con parte de rama horizontal y ascendente, lado izquierdo. No conserva cóndilo ni apófisis coronoides. En la arcada conserva medio M1 y parte del alvéolo de M2. Hay otro pequeño fragmento de la sínfisis, con las geni acusadas y que acusa un probable arco mandibular parabólico cerrado. Otro fragmento de la rama derecha, concordante, solamente parte de la apófisis coronoides. Fragmento de un cóndilo derecho (que parece corresponderse con los siguientes); medidas, $9 \times 15 \mathrm{~mm}$. Índice, 60 . Fragmento de otra rama ascendente derecha, sin el cóndilo ni la coronoides. Fragmento de otra rama ascendente derecha, sólo la apófisis coronoides. Fragmento apical de una coronoides derecha, de poco tamaó y grosor. Fragmento del final de rama horizontal y arranque de ascendente, alvéolo de $M 2$ y parte del M3 iemergido? Hueso robusto. Otro fragmento del lado derecho con el alvéolo de M3. Dientes, raíces de molar inferior, estallada la corona.

Resumen: parcial:

Calota craneal y otros restos de adulto, probable varón.

Otra distinta porción fronto-malar y parte de sutura sagital, de la región mastoidea y mandibular, propios por sus características, de un niño/a.

Son restos que plantean problemas en su adscripción a uno u otro de los tres posibles candidatos y si proceden de una o más cremaciones o de intrusiones fortuitas. En concreto se pueden agrupar asi:

Dos ramas ascendentes izquierdas mandibulares y otras dos derechas. Un cóndilo que podría concordar y, por tanto, representar a dos individuos de anatomía frágil, dada su poca consistencia ósea, pero hay otro fragmento discordante de parte de una pequeña apófisis coronoides, que triplica estos restos mandibulares y craneales.

Los dos pequeños fragmentos mandibulares de aspecto robusto se podrian agrupar con la calota craneal del adulto.

Nuevamente llama la atención la escasa presencia de dientes, habitual en las tumbas de esta necrópolis.

TÓRAX: costillas, fragmentos de cabezas y cuerpos, altura de 10$12 \mathrm{~mm}$. Soldaduras a término. Clavículas, extremidad distal derecha-iz- 
quierda, soldaduras a término. Omóplatos, tres fragmentos con las cavidades glenoideas: una de $29 \times 23 \mathrm{~mm}$ y otros dos de $32 \times 22 \mathrm{~mm}$. EXTREMIDADES: húmeros, epífisis superior, derecha-izquierda, deformes por estrías de cremación; diámetro calculado sobre $40 \mathrm{~mm}$; alto, $25 \mathrm{~mm}$. Diáfisis sobre $16 \times 22 \mathrm{~mm}$; espesor, 3-4 mm. Epífisis inferior, partes de trócleas, fosa perforada, soldadas. Radios, epífisis superior, sólo las cabezas; diámetros de $17 \mathrm{~mm}$ en el derecho y $16 \mathrm{~mm}$ en el izquierdo, tuberosidad bicipital de desarrollo medio; altura de rodete, $7,5 \mathrm{~mm}$. Porción de la epífisis inferior soldadura a término. Cúbitos, epífisis superior, derecha e izquierda, con la porción articular que se articulan con las del húmero. Parte de una epífisis inferior con la apófisis estiloides de poco tamaño. Mano, metacarpiano de tamaño medio. Pelvis, fragmento con parte del acetabulum, concordante con la cabeza femoral, fragmentos de ilíon e isquión. Fémures, epífisis superior, derecha e izquierda, bola articular y parte del cuello, deformadas por estrias crematorias. Diámetros sobre $35 \mathrm{~mm}$; alto, $28 \mathrm{~mm}$. Soldadas, acusada cresta intertrocantérea, cuello sobre $19 \times 28 \mathrm{~mm}$. En otros, partes de línea áspera de poco desarrollo, espesor de paredes de 5 a $6 \mathrm{~mm}$. Epífisis inferiores, partes de la garganta y arranqu de los cóndilos, que acusan un desarrollo medio, soldados. Abundan las esquirlas que no facilitan datos métricos, sólo aparenta la misma contextura y color. Tibia, fragmento de la meseta, soldada, esponjosa compacta; diámetro total transverso calculado sobre $40 \mathrm{~mm}$. Astrágalo, incompleto, impresión de un tamaño medio y concordante con los restos anteriores.

Dada la abundancia de datos de los restos vertebrales los hemos estudiado al final.

VÉRTEBRAS: vértebras cervicales: $1 .^{\circ}$ Atlas, mitad de la misma, que permite calcular un diámetro total sobre $60 \mathrm{~mm}$. $2 .^{\circ}$ Axis, incompleta, altura total de 27 a $30 \mathrm{~mm}$; altura de apófisis, 8 a $9 \mathrm{~mm}$; alto del cuerpo, $20 \mathrm{~mm}$. Cuerpo incompleto; carilla superior, $17 \times 28 \mathrm{~mm}$; ídem inferior, $16 \times 21 \mathrm{~mm}$. Cuerpo incompleto; carilla superior, $15 \times 26 \mathrm{~mm}$. Vértebras dorsales: sólo cuerpos más o menos completos, medidas:

$\begin{array}{llll}\text { Carilla superior } & \text { Carilla inferior } & \text { Canal raquídeo } & \text { Altura } \\ 16 \times 22 \mathrm{~mm} & 17 \times 29 \mathrm{~mm} & 16 \mathrm{~mm} & 16 \mathrm{~mm} \\ 18 \times 24 \mathrm{~mm} & 19 \times 28 \mathrm{~mm} & ? ? & 17 \mathrm{~mm} \\ 18 \times 25 \mathrm{~mm} & 18 \times 29 \mathrm{~mm} & 15 \mathrm{~mm} & 16 \mathrm{~mm} \\ 19 \times 30 \mathrm{~mm} & 21 \times 32 \mathrm{~mm} & 14 \mathrm{~mm} ? & 20 \mathrm{~mm}(\mathrm{~S}) \\ 20 \times 24 \mathrm{~mm} & 21 \times 29 \mathrm{~mm} & 12 \mathrm{~mm} ? & 16 \mathrm{~mm} \\ 21 \times 24 \mathrm{~mm} & 20 \times 25 \mathrm{~mm} & 13 \mathrm{~mm} ? & 16 \mathrm{~mm} \\ 21 \times 25 \mathrm{~mm} & 24 \times 28 \mathrm{~mm} & 14 \mathrm{~mm} ? & 17 \mathrm{~mm}\end{array}$




$\begin{array}{llll}21 \times 30 \mathrm{~mm} & 22 \times 31 \mathrm{~mm} & ? ? & 21 \mathrm{~mm} \text { (S) } \\ 22 \times 20 \mathrm{~mm} & 25 \times 22 \mathrm{~mm} & ? ? & 20 \mathrm{~mm} \\ 22 \times 26 \mathrm{~mm} & 24 \times 29 \mathrm{~mm} & 14 \mathrm{~mm} ? & 18 \mathrm{~mm} \text { (S) } \\ 24 \times 20 \mathrm{~mm} & ? ? & ? ? & ? ? \\ 24 \times 28 \mathrm{~mm} & 25 \times 31 \mathrm{~mm} & 14 \mathrm{~mm} & 20 \mathrm{~mm} \text { (S) } \\ 24 \times 33 \mathrm{~mm} & 24 \times 36 \mathrm{~mm} & 15 \mathrm{~mm} & 19 \mathrm{~mm} \text { (S) }\end{array}$

En total suman 13, por tanto puede ser de dos individuos con una pequeña diferencia de edad, si bien la presencia de $(S)=$ «sindesmofitos» abunda sobre que uno sería mayor que otro. Vértebras lumbares, sólo cuerpos, más o menos completos, medidas:

$\begin{array}{llll}\text { Carilla superior } & \text { Carilla inferior } & \text { Canal raquídeo } & \text { Altura } \\ 21 \times 31 \mathrm{~mm} & ? ? & ? ? & ? ? \\ 24 \times 37 \mathrm{~mm} & 26 \times 41 \mathrm{~mm} & 22 \mathrm{~mm} & 22 \mathrm{~mm} \text { (S) } \\ 26 \times 27 \mathrm{~mm} & 27 \times 38 \mathrm{~mm} & 22 \mathrm{~mm} & 22 \mathrm{~mm} \text { (S) } \\ 28 \times 41 \mathrm{~mm} & 26 \times 42 \mathrm{~mm} & 22 \mathrm{~mm} & 23 \mathrm{~mm} \text { (S) } \\ 28 \times 41 \mathrm{~mm} & 29 \times 45 \mathrm{~mm} & 22 \mathrm{~mm} & 23 \mathrm{~mm} \text { (S) } \\ 28 \times 42 \mathrm{~mm} & 30 \times 45 \mathrm{~mm} & 24 \mathrm{~mm} & 24 \mathrm{~mm} \text { (S) }\end{array}$

En total hay seis, por tanto de dos individuos. La serie de cinco presentan la particularidad de presentar "sindesmofitos" (5) coincidentes en sus tamaños. Sacro, pieza casi completa, con la particularidad de que la primera está sin soldar totalmente, lo que dada edad. Su contextura es más bien pequeña, homobasal, diámetro transverso total sobre $10,5 \mathrm{~cm}$, presenta en su carilla superior un gran sindesmofito izquierdo que concuerda con el de la carilla inferior de la probable quinta vértebra lumbar; diámetros, $28 \times 48 \mathrm{~mm}$. ROA.

CONCLUSIONES: El análisis practicado pone en la pista de la posibilidad de una tumba triple, especialmente por los restos craneales, anatómicamente de un niño/a, una hembra y un varón.

Entre las particularidades de esta completa tumba tenemos que la calota craneal no estaba acompañada por restos aparentes de vértebras ni de las extremidades; si bien, la intensa fracturación dificulta la investigación, mientras que el otro cremado tenía una amplia muestra de todo su esqueleto $y$, si bien, los dientes eran escasos, acusó la presencia del M3 y el sacro que, al no presentar soldada la primera vértebra con la segunda, permite datar su edad menor de 25 años y mayor de 16-18 años, y por su contextura anatómica pensar en que se trata de una hembra $y$ el otro cremado un varón, adulto.

La presencia de "sindesmofitos" en algunas vértebras dorsales, en todas las lumbares y en el sacro -manifestación patológica presente, con 
relativa frecuencia, en cremados de esta necrópolios (ver Boletín, $n .^{\circ} 22$ )es un dato cierto para agrupar estos restos como de un solo individuo, pero quedando otras tres o cuatro vértebras dorsarles sin conexión, dado que sus medidas no concuerdan. Quizá la primera cervical se podría relacionar con el varón, pero sigue en pie la incógnita del tercer pequeño fragmento de apófisis coronoides, al que podríamos agregar estos cuerpos vertebrales de poco tamaño, para plantear la hipótesis de un tercer cremado de menor edad, que debe corresponder el "entrecejo".

T. 540. Esquirlas y pequeños fragmentos de diáfisis y craneales. CRÁNEO: láminas saltadas. Grosores, 4, 6 y 8 ( $F, P$ y $O)$. Suturas de grandes dentellones, sinóstosis interna. Borde orbital frontal fino. Peñasco derecho incompleto, soldado. Malar, reborde orbital fino, redondeado, impresión de ser de poco tamaño. Porción de la apófisis mastoides de poco tamaño. EXTREMIDADES: fragmento de diáfisis de húmero; diámetro en tercio medio sobre $18 \times 15 \mathrm{~mm}$, anteroposterior. Tibia, fragmento de cresta, ángulo abierto. En otro fragmento de fémur línea aspera poco marcada.

Resumen: individuo adulto, alofixo, ¿varón?

T. 541. Gran cantidad de esquirlas y algunos pequeños fragmentos, que en general permiten deducir que proceden de más de un individuo. CRÁNEO: pequeños fragmentos de coloración similar (blanquecina), grosores de 2, 3 y $4 \mathrm{~mm}$, algunos «cascarillas» y suturas de pequeños dentellones, sin soldar. Fragmento de frontal orbitario que articula con la apófosis ascendente del malar, pudiendo deducir una órbita pequeña. Datos que concuerdan hacia un niño/a. VÉRTEBRAS: cuerpo incompleto de vértebra dorsal; altura, $16 \mathrm{~mm}$. EXTREMIDADES: intensa fragmentación que dificultan datos, identificación y métricos, pero que, en general, por los espesores y consistencia parecen proceder de más de un individuo, dato discordante con los fragmentos craneales que parecen infantiles. Húmero, parte de una cabeza articular, sin haber soldado totalmente y cuyo diámetro, calculado, es de $36 \mathrm{~mm}$ ?, paredes de 2 a $4 \mathrm{~mm}$. Omóplato, fragmento de la cavidad glenoides, más pequeño, cuyas medidas están sobre ¿24 × $17 \mathrm{~mm}$ ? Fémur, parte de la epífisis superior, con arranque del cuello y gran trocánter, color negruzco, carbonizado, discordante con la mayoría de las esquirlas, paredes de 6 a $4 \mathrm{~mm}$.

Resumen: restos óseos de dos individuos, uno infantil y otro adulto, sin poder determinar edades.

T. 543. (En el paquete figura también con el n. ${ }^{\circ}$ 542.) CRÁNEO: láminas saltadas, suturas de grandes y medianos dentellones, sinóstosis interna. Grosores de 4 a $6 \mathrm{~mm}$. Fragmento de temporal con arranque de la zigomática muy desarrollada. Malar izquierdo tamaño grande, hueso 
denso, reborde redondeado, grueso, como en otro fragmento de frontal, órbita cuadrangular. EXTREMIDADES: omóplato, fragmento con la cavidad glenoidea incompleta, tamaño grande. Fémur, cabeza o bola articular, incompleta, soldada, grande, isobre $45 \mathrm{~mm}$ ?, que concuerda con fragmento del acetabulum pélvico. Fragmento de diáfisis; diámetro anterior/ posterior, $28 \mathrm{~mm}$; paredes, 5-6 $\mathrm{mm}$. Línea áspera fuerte, desarrollo pilástrico. Rótula grande de $42 \times 45 \times 18 \mathrm{~mm}$.

Resumen: individuo adulto, varón.

T. 544. CRÁNEO: frontal, «entrecejo», glabela voluminosa, borde orbital fino, densa trama trabecular. VÉRTEBRAS: cuerpos incompletos; uno de vértebra cervical, $19 \times 16 \mathrm{~mm}$; otro dorsal, alturas de 15 y $18 \mathrm{~mm}$. Otro lumbar; alto, 23 y $24 \mathrm{~mm}$. Pequeños "sindesmofitos" en algunos fragmentos de ??. EXTREMIDADES: partes de metacarpianos. Radio, epífis inferior soldada, acusada apófisis estiloides; diámetro, $18 \times 20 \mathrm{~mm}$. Fémur, cabeza o bola articular incompleta, grande; diámetro calculado, 38 ó $40 \mathrm{~mm}$, soldada, fuerte trocánter menor. Uno de los cóndilos, esponjosa densa; diámetro calculado de la diáfisis, $60 \mathrm{~mm}$; espesores, 6 a $8 \mathrm{~mm}$. Otro fragmento, línea ásperas prominente; diámetro sobre $29 \mathrm{~mm}$. Rótula, incompleta, grande, $40 \times 44 \times 18 \mathrm{~mm}$ (?). Astrágalo, incompleto; largo sobre $60 \mathrm{~mm}$. ROA.

Resumen: individuo adulto, varón.

T. 545. Se reciben dos «paquetes» con la misma numeración sin datos sobre si proceden de dos depósitos post-cremación o si han sido separados en las operaciones de excavación.

En un primer análisis anatómico general de los dos lotes se aprecia que los restos proceden de dos individuos, si bien hay algunos fragmentos entremezclados, por lo que se procede a un agrupamiento por sus caracteres específicos de coloración, robustez, duplicidad, etc., en dos conjuntos: uno y dos.

Conjunto uno: CRÁNEO: láminas saltadas. Parietal, parte de la sutura sagital de grandes dentellones, sinostosada, grosores de 5-6 mm. Occipital, fragmento con escaso grosor, $3 \mathrm{~mm}$, y relieve de crestas y fosas internas. Mandíbula, fragmento con parte de la escotadura, sin cóndilo ni coronoides, y borde intadurointerno de la sínfisis, con escaso desarrollo de las geni. VÉRTEBRAS: partes de cuerpos, muy fracturados por la cremación, entre los que se distingue la segunda vértebra cervical o axis, muy deforme, de buen tamaño; altura total, $38 \mathrm{~mm}$; de la apófisis, $19 \mathrm{~mm}$. Esquirlas de vértebras dorsales y parte de un cuerpo lumbar, cuya altura se calcula sobre 23-25 mm? EXTREMIDADES: la intensa fracturación dificulta la identificación, que presentan coloración negruzca-carbonosa. Hú- 
mero, porción de la epífisis inferior con la tróclea, de buen tamaño y consistencia trabecular, medidas sobre $35 \times 34 \times 18 \mathrm{~mm}$. Espesores de 3-4 mm. Fémur, medidas en diámetros de la diáfisis sobre $26 \times 27 \mathrm{~mm}$ y espesores 6-7 y $9 \mathrm{~mm}$, fuerte línea áspera y pilastra. Tibia, porción de la meseta, grande y gran consistencia trabecular, diámetro transverso sobre $56 \mathrm{~mm}$. En diáfisis acusada cresta tibial, espesores de $6 \mathrm{~mm}$, ¿platicnemia? Astrágalo, porción de la tróclea, dando impresión de buen tamaño, sobre $45 \mathrm{~mm}$ diámetro transverso.

Resumen: Por aspecto y consistencia de los restos óseos se trata de un individuo varón, adulto, mayor de 25 años.

Conjunto dos: Gran cantidad de esquirlas y fragmentos, que se diferencian del conjunto anterior por la coloración blancuzca y menor espesor de paredes y masa trabecular. CRÁNEO: Láminas saltadas. Grosores de 5 a $8 \mathrm{~mm}$. Suturas sin soldar. Conjunto de frontal, con ambos rebordes orbitales, gruesos, senos grandes, glabela redondeada, arranque de los huesos nasales. Temporal, fragmento de región mastoides, da impresión de grande. Malares, apófisis ascendente. Mandibula, rama horizontal y ascendente izquierda y parte de la derecha. Cóndilo, $7,5 \times 11 \mathrm{~mm}$; escotadura, $22 \mathrm{~mm}$, y coronoides sobre $17 \mathrm{~mm}$ alto. Alvéolos para C-P.P. M1 (raíz), M2 (corona estallada) y M3 (emergiendo); ancho de la rama, $37 \mathrm{~mm}$. TÓRAX: costillas, soldadas, alturas de 13-14 mm. VÉRTEBRAS: vértebras cervicales, axis (como cortado en franja vertical a través de la odontoides; alto total, $31 \mathrm{~mm}$; de la apófisis, $12 \mathrm{~mm}$. Vértebras dorsales, cuerpos deformados; carilla superior, $26 \times 29 \mathrm{~mm}$ y $27 \times 32 \mathrm{~mm}$; e inferiores, $27 \times 28 \mathrm{~mm}$ y $26 \times 29 \mathrm{~mm}$. Serie de cinco vértebras lumbares, medidas:

$\begin{array}{llll}\text { Carilla superior } & \text { Carilla inferior } & \text { Altura } & \text { Canal raquídeo } \\ 26 \times 34 \mathrm{~mm} & 26 \times 42 \mathrm{~mm} & 24 \mathrm{~mm} ? & 22 \mathrm{~mm} \text { (trsv.) } \\ 27 \times 42 \mathrm{~mm} ? & 30 \times 40 \mathrm{~mm} ? & 26 \mathrm{~mm} ? & ? ? \\ 31 \times 42 \mathrm{~mm} ? & 32 \times 439 \mathrm{~mm} ? & 26 \mathrm{~mm} & 22 \mathrm{~mm} \\ 33 \times 44 \mathrm{~mm} & 32 \times 46 \mathrm{~mm} ? & 26 \mathrm{~mm} & ? ? \\ 33 \times 46 \mathrm{~mm} & 35 \times 50 \mathrm{~mm} ? & 26 \mathrm{~mm} ? & 23 \mathrm{~mm}\end{array}$

(están deformadas por estrías crematorias, como curiosidad una de ellas presenta una raíz vegetal que la perfora. Se observan pequeños sindesmofitos). Sacro, fragmento del ala izquierda, de tamaño medio, homobasal?, no presenta partes de los cuerpos vertebrales. EXTREMIDADES: numerosas esquirlas ( 400 a 500 ), color blancuzco, poco espesor de paredes y débil trama trabecular que, sobre todo, se aprecia en epífisis superior de la tibia, dando la impresión de affeción patológica osteopo- 
rótica. Omóplato, parte de la cavidad glenoidea, al parecer no muy grande, de poca consistencia que concuerda con una pequeña porción de la cabeza humeral. Húmero, epífisis superior soldada; cabeza articular; diámetro calculado sobre $37 \mathrm{~mm}$. Espesor de pared, 3-4 mm. Cúbito, en diáfisis; diámetro, $10 \times 11-13 \mathrm{~mm}$. Metacarpiano de $55 \mathrm{~mm}$ de largo. Fémur, epifisis superior soldada, bolar articular; diámetro, $43 \mathrm{~mm}$; alto, $30 \mathrm{~mm}$; diámetro en cuello, $30 \times 23 \mathrm{~mm}$ (dadas las medidas, aunque no concuerda con la coloración de fragmentos, se debía atribuir al otro conjunto de restos y también por la densa estructura trabecular). Tibia, porción de la epífisis superior que presenta la característica de paredes de escaso grosor, tejido trabecular muy esponjoso, iosteoporosis? Cresta tibial redondeada. Una falange sobre $40 \mathrm{~mm}$ y una falangeta gruesa de $22 \mathrm{~mm}$. Astrágalo, incompleto, largo calculado sobre $60 \mathrm{~mm}$; ancho de la tróclea, 29 ó $31 \mathrm{~mm}$ ?

CONCLUSIONES: Se trata de una tumba doble de dos enterramientos, probablemente de un varón, adulto, mayor de 25 años y de una hembra o adolescente de 18 a 20 años.

T. 548. Abundantes esquirlas y pocos fragmentos. CRÁNEO: láminas separadas. Suturas de pequeños dentellones, sin soldar. Grosores de 3 a $6 \mathrm{~mm}$. Mandíbula, fragmento del final de arcede, parece el M3 ocluido. TÓRAX: costillas, partes de cuerpos; altura, $9 \mathrm{~mm}$. VÉRTEBRAS: axis, incompleto de poco tamaño; altura total, $28 \mathrm{~mm}$; de la apófisis, $12 \mathrm{~mm}$. EXTREMIDADES: omóplato, porción de la cavidad glenoidea, de $25 \times$ $20 \mathrm{~mm}$; índice, 80 . Húmero, diámetro en tercio inferior, $16 \times 18 \mathrm{~mm}$; espesor, $4 \mathrm{~mm}$. Un metacarpiano, largo, $43 \mathrm{~mm}$ y una falange de $20 \mathrm{~mm}$. Fémur, fragmento de diáfisis con parte de línea áspera poco marcada; espesor pared, 4-5 $\mathrm{mm}$.

Resumen: individuo adolescente, probable hembra.

\section{RESUMEN}

Se expone detalladamente la «historia" osteológica de 187 cremados de la Necrópolis Ibérica de "El Cigarralejo»: sexo, edad, medidas de epífisis y grosores de pared en los fragmentos más frecuentes, paleontología que presentan, sus interrogantes y conclusiones.

Igualmente, sobre la identificación de las tumbas dobles y de las infantiles.

Palabras claves: Cremación, Osteología, Paleopatología. 
SUMMARY

The osteologic "history» of 187 cremations from the «Necrópolis Iberica de el Cigarralejo" is expounded in detail: sex, age, epiphysis, measurements, thickness of the most frequent pieces, and palaeopathology features, as well as some and conclusions.

At the same time, it will deal with Children's and double graves identification.

Key words: Cremation. Osteologic. Palaeopathology. 